\title{
NOVOS PARÂMETROS PARA O PODER DE COMPRA DO ESTADO
}

\author{
DiSSERTAÇÃO DE MESTRADO
}

Orientador: Prof. Titular Dr. Gilberto Bercovici

UNiVERSidAde de SÃo PaUlo

FACULDADE DE DIREITO

São Paulo (SP)

2017 

Rafael Carvalho de Fassio

NOVOS PARÂMETROS PARA O PODER DE

COMPRA DO ESTADO

Dissertação apresentada à Banca Examinadora do Programa de Pós-Graduação em Direito, da Faculdade de Direito da Universidade de São Paulo, como exigência parcial para a obtenção do título de Mestre em Direito, na área de concentração "Direito Econômico", sob a orientação do Prof. Titular Dr. Gilberto Bercovici.

UNiVersidade de São PaUlo

FACULDADE DE DIREITO

SÃo Paulo (SP)

2017 


\section{Catalogação da Publicação \\ Serviço de Biblioteca e Documentação \\ Faculdade de Direito da Universidade de São Paulo}

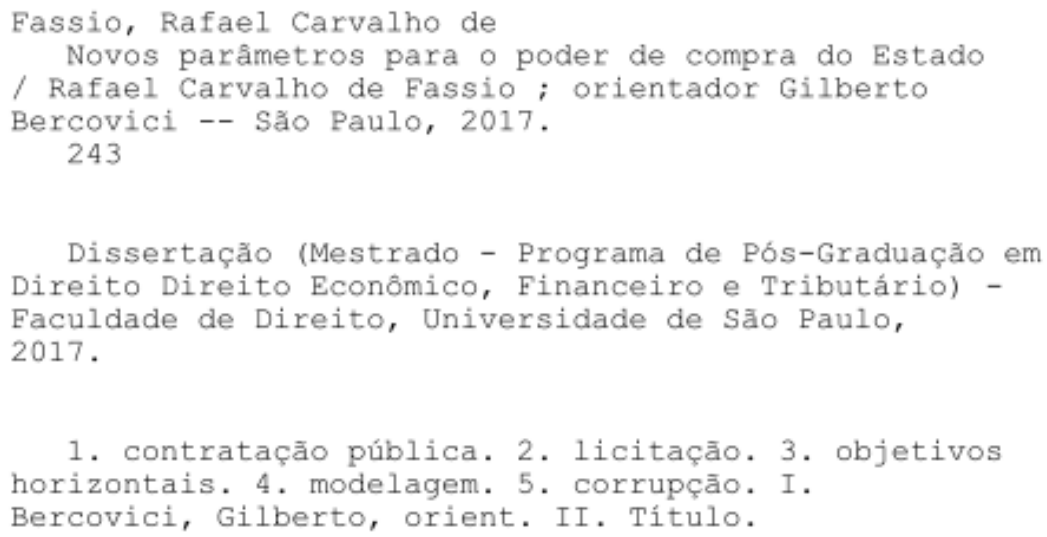

*Ficha catalográfica gerada automaticamente pelo link: http://www.direito.usp.br/biblifd/ficha.php 


\section{AGRADECIMENTOS}

Umberto Eco, em seu célebre “Come si fa una tesi di láurea”, recomenda que não se agradeça demasiadamente ao orientador porquanto a sua ajuda já seria, em grande parte, parte de seu encargo na pesquisa. Contudo, vejo-me obrigado a divergir desse conselho e a inaugurar estas linhas agradecendo imensamente ao meu orientador, Gilberto Bercovici. O Gilberto aceitou-me como orientando pela primeira vez ainda no segundo ano da minha graduação em Direito na USP, quando fui bolsista de Iniciação Científica da Fundação de Amparo à Pesquisa do Estado de São Paulo - FAPESP. Desde então, passados quase dez anos desde que o abordei de surpresa, ao sair da passarela do segundo andar da Faculdade, o Gilberto nunca deixou de acreditar no meu potencial e influenciou como poucos as minhas decisões acadêmicas e profissionais. Sua trajetória de sucesso é um exemplo para mim.

Agradeço aos Professores Luis Fernando Massonetto e Úrsula Dias Peres, que integraram minha banca de qualificação, por terem contribuído com importantes observações e sugestões. Também sou grato a Alexandre Ribeiro Motta (ESAF) e a Eduardo Pedral Sampaio Fiuza (IPEA) pelos pertinentes comentários sobre os aspectos econômicos da pesquisa, os quais foram incorporados, sempre que possível, na versão final desta Dissertação de Mestrado.

Devo muito à Faculdade de Direito da Universidade de São Paulo por ter viabilizado meu intercâmbio na Università degli Studi di Roma II "Tor Vergata”, onde pude entrar em contato com outra realidade acadêmica e com outros materiais de pesquisa, o que produziu reflexos indeléveis para esta investigação.

Não poderia deixar de agradecer à Procuradoria Geral do Estado de São Paulo, cujos quadros tenho a honra de integrar desde 2013. Aos meus eternos colegas da Consultoria Jurídica da Secretaria da Segurança Pública, onde passei meus três primeiros anos de carreira, sou grato pela amizade e pela troca constante de ideias diante dos vários impasses e perplexidades que os problemas do dia-a-dia da Adminsitração Pública nos apresentam. Agradeço ao Procurador do Estado Chefe, Dr. Valter Farid Antonio Junior, representando toda a equipe de Procuradores do Estado e servidores. Guardo imenso orgulho por termos sido, todos juntos, finalistas da edição de 2015 do "Prêmio Mario Covas" com o nosso projeto de padronização de editais e racionalização de trabalho em licitações e contratos.

À Subprocuradora Geral do Estado da Consultoria, Dra. Cristina M. Wagner Mastrobuono, e a todo o seu valoroso time de assessores, deixo o meu muito obrigado pela harmonia do convívio diário e por terem me concedido a oportunidade, desde março de 2016, 
de enfrentar alguns dos diversos desafios que chegam todos os dias ao Gabinete da PGE. Foi nesta escola em que eu aprendi que a missão da Advocacia Pública não está só em dizer o "não" quando necessário, mas sim na árdua tarefa de construir e viabilizar o "sim" que, com respeito à legalidade e ao interesse público, permitirá ao Estado brasileiro desempenhar a multiplicidade de tarefas que a Constituição da República lhe prescreve.

O apoio financeiro do Centro de Estudos da PGE foi imprescindível para a aquisição das obras estrangeiras que integram grande parte da bilbiografia desta Dissertação de Mestrado, ante a escassez de literatura nacional sobre o tema. Agradeço à Dra. Mariangela Sarrubbo Fragata por ter me convidado a integrar a Comissão Editorial da Revista da Procuradoria Geral do Estado de São Paulo, na demonstração de que a crítica é o melhor caminho para o aperfeiçoamento acadêmico. Também sou grato aos Professores Haroldo Pereira e Roberto Augusto Castellanos Pfeiffer pelo convite para fazer parte da equipe do Curso de Especialização em "Direito e Economia" na Escola Superior da Procuradoria Geral do Estado de São Paulo - ESPGE, onde pude refletir sobre muitas das questões abordadas neste trabalho.

Quero demonstrar a minha gratidão, igualmente, a Maria de Fátima Alves Ferreira e a Cristiane Maria Marques Cardoso, da Secretaria de Estado da Fazenda, pela valorosa parceria que já nos tem permitido colocar em prática, no âmbito da Bolsa Eletrônica de Compras do Estado de São Paulo (BEC/SP), algumas das ideias que defendo ao longo deste estudo.

Deixo também o meu muito obrigado a Liliana Picchi Cappuccelli, que passou a partilhar muitas das minhas indignações sobre a rigidez e o formalismo da legislação brasileira de licitações e contratos no período em que estagiou na Consultoria Jurídica da Secretaria da Segurança Pública. Seu interesse no tema e sua valiosa ajuda contribuiram muito para que essa Dissertação de Mestrado viesse a lume, sobretudo com a revisão crítica dos meus resumos e anotações.

Por fim, não preciso de maiores explicações para agradecer aos meus pais, Leonardo e Mariangela, e a todos os meus amigos e familiares. A eles, e a Deus, eu devo o que sou e tudo o que conquistei até aqui. 


\section{RESUMO}

FASSIO, Rafael Carvalho de. Novos parâmetros para o poder de compra do Estado. $243 \mathrm{f}$. Mestrado - Faculdade de Direito, Universidade de São Paulo, São Paulo, 2017.

Situada na fronteira entre o Direito e a Economia, a contratação pública desempenha um papel fundamental nos países em desenvolvimento. Entretanto, no Brasil, as limitações do marco legal que disciplina as licitações e os contratos têm comprometido a eficiência das contratações de bens e serviços pelo Poder Público. Com efeito, as normas rígidas e inflexíveis estabelecidas pela Lei $\mathrm{n}^{\circ}$ 8.666/1993 preocupam-se sobretudo com o desperdício ativo e com a ocorrência de conluio e práticas de corrupção, gerando fracos incentivos para reduzir custos de transação e melhorar a oferta de qualidade contratável e não contratável. Nessa linha, nem sempre a licitação irá conduzir a Administração Pública à proposta mais vantajosa, notadamente diante de objetos complexos e de fatores como incompletude contratual, assimetrias de informação e concentração de mercado. Existe um trade off entre concorrência e complexidade do objeto que não é adequadamente considerado pela legislação brasileira, a qual fixou ex ante as minúcias e os detalhes dos procedimentos aplicáveis a cada modalidade. Por isso, acredito que a modelagem da licitação e o design do ajuste podem constituir ferramentas de relevo para aumentar a eficiência dos contratos públicos e, concomitantemente, combater de forma mais efetiva o conluio e a corrupção. Além disso, correspondendo a cerca de $15 \%$ do PIB brasileiro, as contratações governamentais são um instrumento poderoso para atingir objetivos horizontais, por meio da demanda gerada pelo poder de compra do Estado. Por exemplo, o interesse crescente no emprego das licitações para tutelar o meio ambiente e estimular o desenvolvimento de novas tecnologias é um fator que contribui para questionar o primado do "menor preço" como critério de julgamento e, também, efetivar objetivos e finalidades que transcendem o objeto do contrato.

Palavras chave: contratação pública; poder de compra; objetivos horizontais; concorrência; corrupção; modelagem do procedimento. 


\begin{abstract}
FASSIO, Rafael Carvalho de. New guidelines concerning the purchasing power of the State. 243 f. Master - Faculty of Law, University of São Paulo, São Paulo, 2017.

At the intersection of law and economics, public procurement has a key role to play in developing countries. However, in Brazil, an outdated legal framework serves as a limitation to efficiency regarding public purchase of goods and services. The strict and inflexible rules set forth by Federal Law no. 8.666, enacted in 1993, focused most of their attention in fighting active waste, collusion and corruption, whereas it provides little incentive to minimize transaction costs and increase verifiable and non-verifiable quality. A competitive tendering does not always results in best value of money to the buyer, mostly in complex objects and incomplete contracts, when information is asymmetric and there is a limited number of players in the market. I argue that there is a tradeoff in procurement between competition and complexity that is not regarded by the current legal framework, which ex ante sets forth the particular details of applicable tendering procedures. Thus, I aim to outline some procurement design and contracting strategies that could improve efficiency of public contracting while fighting corruption and preventing collusion at the same time. Moreover, accounting for $15 \%$ of GDP in Brazil, I argue that public procurement can be a strategic economic policy tool on the demand-side in order to achieve relevant horizontal policies through the purchasing power of the State. For example, a growing interest in green and innovation procurement has recently shed light on non-price attributes as selection criteria, aiming goals and targets that go beyond the object of the contract.
\end{abstract}

Key words: public procurement, purchasing power; horizontal policies, competition; corruption; procurement design. 


\section{SUMÁRIO}

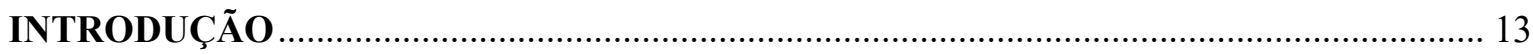

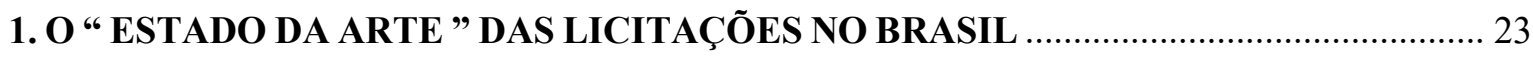

1.1. Das finanças Públicas ao Direito administrativo: as quatro fases das LICITAÇÕES NO BRASIL

1.1.1. Primeira fase: o Código de Contabilidade e a "centralização das compras" das décadas de 1930 e 1940. 27

1.1.2. Segunda fase : unificação nacional e simplificação das regras pelo Decreto-Lei $\mathrm{n}^{\mathrm{o}}$ $200 / 1967$

1.1.3. Terceira fase : o Decreto-Lei $n^{\circ}$ 2.300/1986, a Lei $n^{\circ} 8.666 / 1993$ e o triunfo do

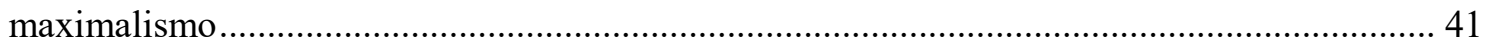

1.1.4. Quarta fase: a "fuga" das licitações e a erosão do modelo unitário de contratações

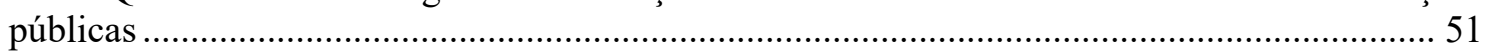

1.1.4.1. As reformas no regime jurídico das contratações públicas em geral ......................... 54

1.1.4.2. As reformas no regime jurídico das contratações públicas específicas....................... 58

1.1.5. A perseverança de um marco legal em crise............................................................... 74

1.2. Do Direito Administrativo ao Direito ECONÔMICO: A ECONOMIA DAS LiCITAÇões E O “CUSTO INVISÍVEL” DO REGIME JURÍDICO ADMINISTRATIVO_............................................... 77

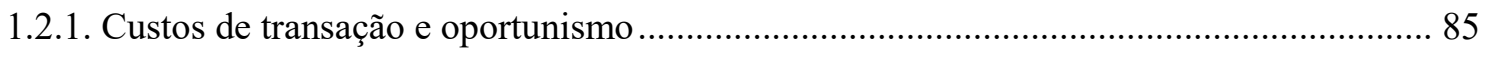

1.2.2. Complexidade do objeto e incompletude contratual ...................................................... 91

1.2.3. A contratação pública sob as lentes do Direito Econômico............................................... 94

2. O PODER PÚBLICO COMO CLIENTE: EQUÍVOCOS ENVOLVENDO O PODER DE COMPRA DO ESTADO NA LEGISLAÇÃO FEDERAL BRASILEIRA ................................ 99

2.1. OBJETIVOS “HORIZONTAIS", “MEDIATOS" OU "EXTRACONTRATUAIS": FUNÇÃO

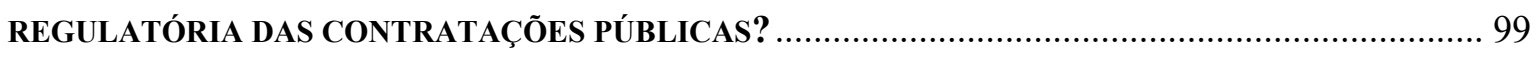

2.1.1. A "economia da discriminação" e os contratos públicos no comércio internacional....... 104

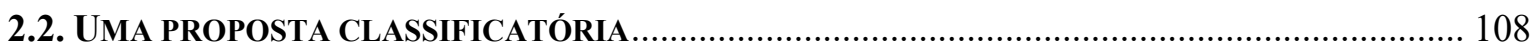

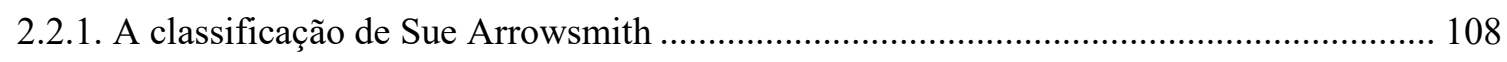

2.2.2. Objetivos pré-procedimentais, intraprocedimentais, extraprocedimentais e contratuais 111

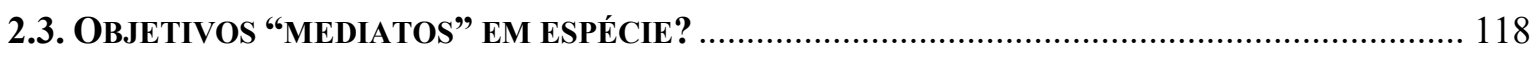

2.3.1. Incentivo a Microempresas e Empresas de Pequeno Porte.............................................. 118

2.3.2. Desenvolvimento sustentável, "compras verdes" e contratações públicas ecoeficientes. 125

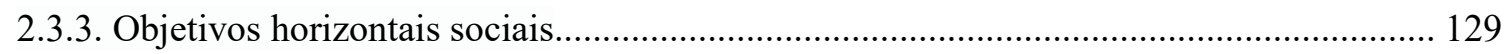

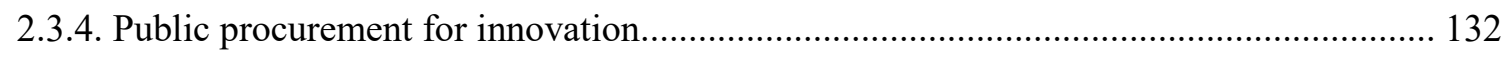

2.3.5. Desenvolvimento nacional : a "margem de preferência" para produtos e serviços

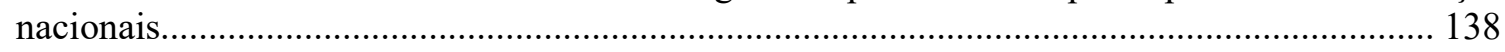


2.4. O "BLOQUEIO" DOS OBJETIVOS HORIZONTAIS PELA JURISPRUDÊNCIA DO SUPREMO

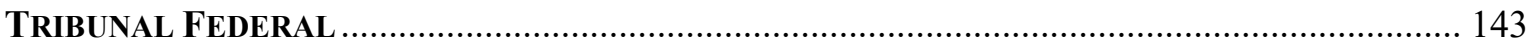

2.5. A POSTURA DEFENSIVA dOS GESTORES DE COMPRAS E A INEFETIVIDADE DOS OBJETIVOS

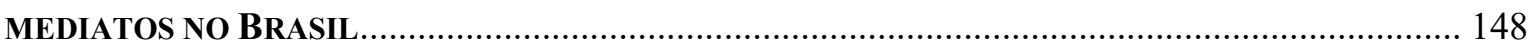

3. NOVOS PARÂMETROS PARA O PODER DE COMPRA DO ESTADO 153

3.1. A "MODELAGEM" DO PROCEDIMENTO LiCITATÓRIO PARA AUMENTAR OU DIMINUIR A

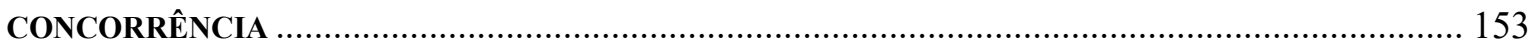

3.1.1. Licitações e contratos rumo ao Direito da Concorrência .................................................. 153

3.1.2. A "modelagem” da licitação à luz da teoria dos leilões ................................................. 157

3.1.3. Impactos concorrenciais de alguns aspectos do procedimento licitatório ......................... 161

3.1.4. Tipos de contratos e alocação de riscos : contratos de preço fixo, de reembolso e de incentivo

3.1.5. Qualidade contratável e não contratável. "Implicit contracting" e incentivos à

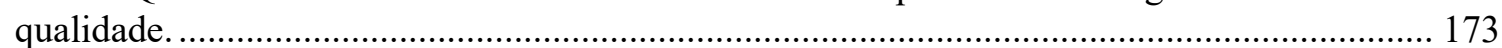

3.1.6. Restringir a concorrência pode ser benéfico? A complexidade do objeto e a escolha entre leilões e negociações.

3.2. A "MODELAGEM" do PROCEDIMENTO LiCITATÓRIO PARA PREVENIR FRAUdES E A CORRUPÇÃO EM LICITAÇÕES

3.2.1. Quis custodiet ipsos custodes? A Economia Política da Corrupção aplicada às contratações públicas

3.2.2. Coordenação e enforcement: dois desafios para a atuação de cartéis em licitações 199

3.2.3. Fatores pró e anticorrupção em licitações e contratos públicos ........................................ 204

3.2.3.1. Fatores pró e anticorrupção decorrentes de fatores estruturais.................................. 204

3.2.3.1.1. Número de competidores e barreiras à entrada ................................................ 204

3.2.3.1.2. Disponibilidade de informações sobre o certame .............................................. 206

3.2.3.1.3. Assimetrias e heterogeneidade ....................................................................... 207

3.2.3.1.4. Centralização e descentralização das contratações públicas ........................... 208

3.2.3.2. Fatores pró e anticorrupção decorrentes da modelagem da licitação e do contrato... 211

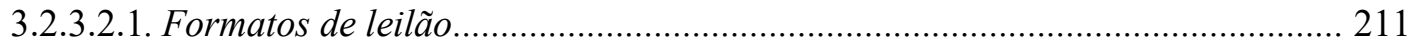

3.2.3.2.2. "It takes time to make friends" : a dimensão temporal da corrupção em

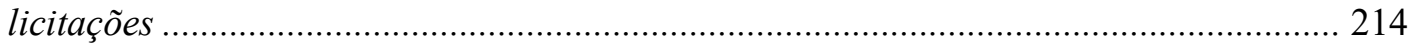

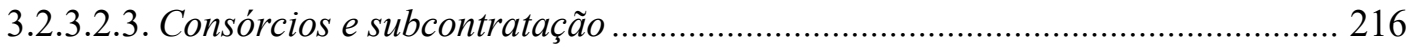

3.2.4. O locus da corrupção na contratação pública ................................................................... 217

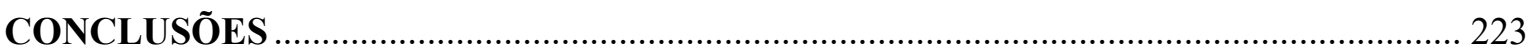

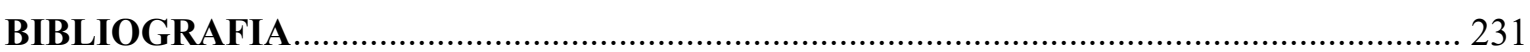

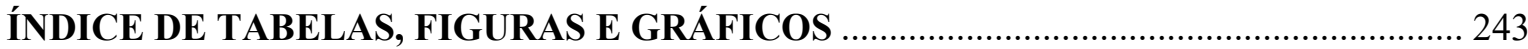


"(...) governments have in the past with few exceptions notoriously failed as purchasers. (...) Dealers complain of red tape which hampers them in bidding, in delivering goods and in securing the payment of bills. Government executives themselves complain of delays between the issue of purchase acquisitions and the availability of goods for use. Citizens generally are prone to assert that graft and political favoritism taint a large part of government purchasing".

THOMAS, Arthur G. Principles of Government Purchasing. New York: D. Appleton and Company, 1919, p. 5. 



\section{INTRODUÇÃO}

Em uma tarde do mês de maio de 2013, chegava à Consultoria Jurídica da Secretaria da Segurança Pública uma consulta incomum. Após décadas de prestação irregular por meio de depositários, o Estado de São Paulo pretendia licitar pela primeira vez os serviços de pátios e guinchos para custodiar cerca de noventa mil veículos apreendidos pelas Delegacias de Polícia da capital. À época, a situação dos pátios existentes era absolutamente caótica e, além disso, havia diversas decisões judiciais condenando a Fazenda Pública a remover, sob pena de multa diária, os veículos cujas carcaças já em decomposição se empilhavam aos montes em ruas, parques e áreas de mananciais ${ }^{1}$. Algo precisava ser feito urgentemente, mas os técnicos da Secretaria não sabiam como estruturar a contratação que regularizaria as apreensões de veículos na Grande São Paulo e, por isso, formularam uma consulta à Procuradoria Geral do Estado.

Ao ler o processo, logo percebi que o objeto tinha peculiaridades que não encontrei nos livros e manuais de Direito Administrativo, aos quais geralmente recorria para esclarecer as dúvidas do quotidiano. O mercado de pátios era altamente concentrado, pois a demanda era quase que integralmente estatal - tanto que os poucos prestadores, naquela ocasião, já se articulavam nos bastidores com a certeza de que, qualquer que fosse a modalidade eleita pelo Poder Público, se sagrariam vencedores do procedimento licitatório. Some-se a isso uma assimetria informacional avassaladora que tornava extremamente incertos os custos que deveriam ser suportados pelo Erário. Sem parâmetros seguros em que se fiar, as pesquisas de mercado resultaram em valores de referência irreais e muito superiores ao orçamento disponível, alçando rapidamente a licitação a patamares multimilionários.

Eu sabia que a contratação pública a ser desenhada deveria dialogar com todos esses fatores para neutralizar na maior medida possível os riscos para o Estado de São Paulo enquanto contratante. Compulsei a legislação, reli os livros, mas eu não conseguia encontrar uma solução que atendesse de uma só vez as necessidades da Secretaria da Segurança Pública. Julguei-me inexperiente, porquanto havia tomado posse no cargo de Procurador do Estado de São Paulo havia apenas alguns meses. Mas minha consulta a tantos outros colegas

\footnotetext{
${ }^{1}$ A situação chegou inclusive a ser noticiada pela imprensa: ARCOVERDE, Léo. "Veículo aprendido vai para pátio ilegal de ex-PM na Grande SP" Folha de São Paulo. São Paulo, 22/10/2012. Disponível em: http://www1.folha.uol.com.br/cotidiano/1172966-veiculo-apreendido-vai-para-patio-ilegal-de-ex-pm-na-gran de-sp.shtml. Acesso em 05/01/2017 e LIMA, Bianca Pinto. “À espera de licitações, motoristas sofrem com burocracia de pátios e guinchos". O Estado de São Paulo. 29/01/2015. Disponível em: http://brasil.estadao.com.br/noticias/geral,a-espera-de-licitacoes-motoristas-sofrem-com-burocracia-de-patios -e-guinchos. Acesso em 05/01/2017.
} 
mais experimentados e mesmo às instâncias superiores da Procuradoria resultaram todas em um mesmo e único diagnóstico: era a própria legislação brasileira de licitações e contratações públicas que não fornecia uma resposta adequada para o problema enfrentado pela Administração.

Ao final, a situação concreta envolvendo os veículos apreendidos em razão de atos de polícia judiciária foi equacionada mediante um arranjo contratual complexo que reuniu dois pregões, um credenciamento e pelo menos de uma dezena de leilões ${ }^{2-3}$. Mas esse impasse, repetido tantas outras vezes em um sem-número de casos semelhantes, despertou a minha atenção para o fato de que o Estado brasileiro tem diante de si um repertório bastante restrito de alternativas para licitar e contratar os bens e os serviços necessários à consecução de suas atividades-meio e atividades-fim ${ }^{4}$. Esse quadro, agravado pela qualidade sofrível dos objetos contratados pelo Poder Público, expõe com clareza uma contradição entre a rigidez e o formalismo da legislação no Brasil e a descoberta, tão frequente quanto vergonhosa, de novas fraudes envolvendo licitações toda a semana nas manchetes dos jornais.

A Lei $n^{\circ} 8.666 / 1993$ ocupa o epicentro de um caloroso debate entre seus defensores - ligados, normalmente, ao discurso de combate à corrupção - e seus opositores, que criticam as dificuldades criadas pela legislação no que se refere à gestão pública ${ }^{5}$. A burocracia, alvo

\footnotetext{
2 “A estrutura dos pátios contratados pela Polícia Civil conta com iluminação, piso pavimentado, sistema de vigilância com câmeras em HD e seguro. Haverá postos do Instituto de Criminalística (IC) nos locais, com o objetivo de acelerar o trabalho de perícia, vistoria e liberação dos veiculos que podem retornar aos donos. Como esses veículos podem ser compactados a partir de uma autorização judicial, os grandes estacionamentos terão áreas destinadas a leilões, descontaminação e compactação. Esse procedimento já está sendo realizado no Pátio Santo Amaro, na capital. Até agora, 10.072 veículos foram compactados e cerca de 50 mil carcaças serão limpas e destruídas". "SP INICIA REMOÇÃO DE VEÍCULOS apreendidos em delegacias para pátios". Radar Nacional (R7). São Paulo, 14/09/2015. Disponível em: http://www.radarnacional.com.br/sp-iniciaremocao-de-veiculos-apreendidos-em-delegacias-para-patios/. Acesso em 05/01/2017.

3 "No pátio de Santo Amaro serão compactados [descontaminados e então compactados] 13.500 veículos, dos quais $62 \%$ já estão liberados. 'Fizemos um leilão para a empresa que fará a compactação de dessas carcaças, e temos uma licitação aberta para mais 32 mil. [Ao todo], chegaremos a 45 mil veículos', informou o governador Geraldo Alckmin. A medida é o primeiro passo para resolver uma questão de mais de 25 anos, gerada por entraves judiciais que impediam a liberação desses veículos dos pátios. Em maio do ano passado, a Justiça autorizou que fossem realizados leilões dos 45 mil veículos apreendidos em pátios na cidade de São Paulo, atendendo a um pedido da Secretaria da Segurança Pública". "VEÍCULOS APREENDIDOS NA CAPITAL começam a ser compactados" SP Notícias - Portal de Notícias do Governo do Estado de São Paulo. São Paulo, 17/02/2014. Disponível em: http://www.saopaulo.sp.gov.br/spnoticias/lenoticia.php?id=235801\% C3\%A0. Acesso em 05/01/2017.

${ }^{4}$ Sobre a distinção entre atividades-meio ("non core") e atividades-fim ("core"), confira CICOGNA, Cristina. "L'outsourcing delle funzioni strumentali della Pubblica Amministrazione". In: FIORENTINO, Luigi (org.). Lo stato compratore. L'acquisto di beni e servizi nelle publiche amministrazioni. Bologna: Il Mulino, 2007, pp. $25-45$.

5 "(...) argumenta-se que a Lei 8.666/1993 é burocrática demais e que, em função dela, as obras se atrasariam excessivamente. A Lei Geral de Licitações e Contratos, sob a perspectiva da gestão pública, seria um peso e um obstáculo à boa administração". ROSILHO, André Janjácomo. Licitação no Brasil. São Paulo: Malheiros, 2013, p. 19.
} 
frequente das críticas dos gestores, é comumente vista como um “mal necessário" para coibir desvios e fraudes. Isso, porém, com base na premissa (errada) de que o estrito cumprimento do rito legal já seria, por si só, um remédio eficaz contra o conluio, a captura e a corrupção em certames licitatórios. Por exemplo, um levantamento realizado por Laura CARPINETI, Gustavo PigA e Matteo ZANZA revelou que o Brasil exige o maior número de requisitos para a participação de fornecedores em licitações entre os 21 países consultados ${ }^{6}$. Todavia, não é possível afirmar que toda essa profusão de requisitos de habilitação tenha alcançado particular êxito para a moralização das contratações públicas realizadas em nosso país. Pelo contrário: o apego burocrático dos órgãos de controle interno e externo não apenas falha em fornecer incentivos adequados para coibir a corrupção como também pode servir, inversamente, para chancelá-la, revestindo práticas escusas com um manto de aparente legalidade ${ }^{7}$.

Por outro lado, o poder de compra do Estado é um componente importante da demanda do setor público. No Brasil, estima-se que as contratações firmadas pela Administração Pública movimentem cerca de 60 bilhões de reais por ano, o que representa $15 \%$ do PIB brasileiro ${ }^{8}$. As contratações públicas correspondem, em média, a cerca de 13\% do PIB e representam $29 \%$ do total de gastos governamentais dos países membros da $\mathrm{OCDE}^{9}$, podendo inclusive chegar a $15 \%$ do produto mundial ${ }^{10}$. Em países em

\footnotetext{
${ }^{6}$ CARPINETI, Laura; PIGA, Gustavo; ZANZA, Matteo. "The variety of procurement practice: evidence from public procurement". In: DIMITRI, N.; PIGA, G.; SPAGNOLO, G. (Ed.). Handbook of procurement. Cambridge (UK): Cambridge University Press, 2006. pp. 14-44. cf. pp. 17-19.

${ }^{7}$ É curioso destacar como as auditorias realizadas pelos órgãos de controle apegam-se normalmente a detalhes menores do procedimento licitatório, tais como a numeração e a rubrica dos servidores nas folhas do processo e a observância dos prazos mínimos para publicação do "aviso" no Diário Oficial e nos jornais de grande circulação, mas pouco falam sobre a pesquisa de preços e a coleta de orçamentos que, não raras vezes, usam valores irreais para calcular o valor de referência da licitação.

${ }^{8}$ Segundo dados da Secretaria de Assuntos Legislativos do Ministério da Justiça, somando-se as Administrações direta e indireta da União, Estados e Municípios. NOHARA, Irene Patrícia "Poder de compra governamental como fator de indução do desenvolvimento - faceta extracontratual das licitações". Revista Fórum de Direito Financeiro e Econômico - RFDFE. Belo Horizonte, ano 4, n. 6, set./fev. 2015, p. 164.

${ }^{9}$ Com base em estatísticas da OCDE, em 2011, "[g]eneral government procurement spending represents $29 \%$ of total general government expenditures $(13 \%$ of GDP)". Disponível em: $<$ http://www.oecd.org/gov/ethics/public-procurement.htm>. Acesso em 12/06/2016. Confiram-se também os dados constantes do relatório elaborado pelo Banco Mundial sobre as contratações públicas no Brasil. BANCO MUNDIAL. Brazil - Country procurement assessment report. Washington (DC): World Bank, 2004. Disponível em: http://documents. worldbank.org/curated/en/2004/03/3575914/ brazil-country-procurement assessment-report. Acesso em 12/06/2016.

10"Public procurement is said to account for between 15 and 20 percent of the GDP of most countries". PIGA, Gustavo. "A fighting chance against corruption in public procurement?" In: ACKERMAN, Susan Rose; SOREIDE, Tina (org.). International Handbook on the Economics of Corruption. Vol. II, Cheltenham (UK): Edward Elgar, 2011, pp. 141-181. No mesmo sentido: BAJARI, Patrick e LEWIS, Gregory. "Procurement Contracting With Time Incentives: Theory and Evidence". The Quarterly Journal of Economics, Oxford University Press, vol. 126 (3), 2011, pp. 1173-1211.
} 
desenvolvimento, segundo William KOVACIC, a proporção dos contratos públicos em relação ao PIB pode atingir a impressionante cifra de $40 \%{ }^{11}$. Esses números evidenciam que o emprego do potencial gerado pelas contratações públicas pode desempenhar funções relevantes para não apenas para corrigir falhas de mercado - com as funções alocativa (alocação ótima dos recursos disponíveis), distributiva (redistribuição da renda) e estabilizadora (estabilização macroeconômica), na trilogia neoclássica proposta por Richard MUSGRAVE $^{12}$ - mas também para efetivar políticas públicas e alcançar objetivos horizontais, indiretos, mediatos ou extracontratuais desejados pelo Estado brasileiro. Entre eles, por exemplo, a inclusão de práticas de sustentabilidade ambiental nas licitações, como especificação técnica do objeto ou obrigação acessória da contratada, nos termos do Decreto $n^{0}$ 7.746, de 05 de junho de 2012; a ampliação do acesso de Microempresas e Empresas de Pequeno Porte ao mercado público, dada pela Lei Complementar $n^{\circ} 123$, de 14 de dezembro de 2006; e, ainda, a "margem de preferência" estabelecida pela Lei no 12.349, de 15 de dezembro de 2010, para a aquisição de bens e serviços nacionais, como estímulo à política industrial.

Até aqui, minha pesquisa tem revelado que a pouca efetividade das medidas administrativas e legislativas voltadas a promover o poder de compra do Estado - fato largamente constatado do dia-a-dia da Administração Pública brasileira ${ }^{13}$ - é só parte do problema. Sob a perspectiva das ciências econômicas, a modelagem do procedimento licitatório e da contratação pública constituem um instrumento poderoso para canalizar a demanda criada pelo Estado-comprador em prol de objetivos contratuais ou extracontratuais relevantes. O direito comparado é rico em experiências nesse sentido ${ }^{14}$. Mas a aplicação

\footnotetext{
${ }^{11}$ KOVACIC, William E. "Competition policy, consumer protection and economic disadvantage". Washington University Journal of Law \& Policy. Vol 25, 2007, pp. 101-118, p. 101.

${ }^{12}$ A conhecida abordagem de Richard Musgrave sobre as funções econômicas do setor público foi exposta em um artigo intitulado "Voluntary Exchange Theory of Public Economy", publicado em 1939 no Quarterly Journal of Economics. Enfatizando a importância desses contratos para a função estabilizadora, confira RODRIGUES, Nuno Cunha. A Contratação Pública como Instrumento de Política Económica. Coimbra: Almedina, 2013, p. 25, nt. 43.

${ }^{13}$ Este fato é reconhecido pelo próprio governo federal, que tem realizado sucessivos eventos e iniciativas para divulgar aos órgãos e entidades a adoção de licitações e contratações públicas sustentáveis. Além de ser discutida em seminários e congressos, essa "advocacia" da sustentabilidade enquanto objetivo horizontal das contratações públicas ganhou um portal pemanente na página do Ministério do Planejamento, Orçamento e Gestão, no seguinte endereço: http://cpsustentaveis.planejamento.gov.br/

${ }^{14}$ Há uma extensa literatura estrangeira sobre teoria dos leilões que se volta especificamente à sua aplicação pelo Poder Público. Confiram-se, nesse sentido, ALBANO, G. L.; DIMITIRI, N.; PERRIGNE, I.; PIGA, G.; "Fostering Participation". In: DIMITRI, N.; PIGA, G.; SPAGNOLO, G. (Ed.). Handbook of procurement. Cambridge (UK): Cambridge University Press, 2006, pp. 267-292; MILGROM, Paul. "Putting auction theory to work: the simultaneous ascending auction". Journal of Political Economy, vol. 108, n 2, 2000, pp. 245-272; KLEMPERER, Paul. Auctions: theory and practice. Princeton (NJ); Oxford (UK): Princeton University Press,
} 
desses mesmos mecanismos no Brasil encontra óbices no formalismo e na rigidez da própria legislação, que fixou, em detalhes, os procedimentos aplicáveis a cada modalidade de licitação.

Este trabalho tem como objetivo questionar os pressupostos sobre os quais se erige a legislação brasileira de licitações e contratos. Para tanto, não se pode olvidar que a expressiva demanda gerada pelo setor público constitui uma dentre várias técnicas jurídicas postas à disposição do Estado para realizar a sua política econômica, amoldando-se com perfeição ao objeto de estudo do Direito Econômico ${ }^{15}$. Tenho consciência de que a análise de um instituto tão caro ao Direito Administrativo sob o viés da Economia acarreta desafios adicionais, como a percepção de que as justas preocupações com a eficiência das contratações celebradas pelo Poder Público não podem se sobrepor à legalidade, à moralidade, à impessoalidade e à publicidade consagradas pelo artigo 37, caput da Constituição da República. Por isso, reputo importante destacar desde logo que a análise empreendida nestas linhas se situa propositadamente fora do campo da lege lata, e não se propõe à aplicação imediata e irrefletida de instrumentos vigentes no estrangeiro ao ordenamento jurídico brasileiro. A incursão analítica que pretendo realizar, sobretudo no que se refere ao design dos procedimentos licitatórios e dos contratos, almeja apenas revelar potencialidades que a legislação vigente, preocupada em restringir a discricionariedade do administrador, bloqueia. Ora, se o modelo legal foi elaborado com base em pressupostos incorretos sob o ponto de vista jurídico e econômico é justo que essas mesmas inconsistências sejam reveladas e criticadas com base em argumentos, igualmente, jurídicos e econômicos.

Cabe aqui tecer um breve comentário sobre a nomenclatura a que faremos referência ao longo de todo o presente estudo. Segundo Nuno Cunha RODRIGUES, não há uma terminologia clara e unívoca para denominar o amplo universo das contratações firmadas por órgãos e entidades estatais ${ }^{16}$. Nos países de língua inglesa, é bastante difundido

\footnotetext{
2004, especialmente o cap. 1 “A survey of auction theory”, pp. 09-61; e KRISHNA, Vijay. Auction Theory. $2^{\text {nd }}$ edition. Oxford (UK): Academic Press/Elsevier, 2010, pp. 01-07, 173-184.

15 Sobre o tradicional debate que situa o Direito Econômico não como "ramo", mas como "método" para a análise e (re)compreensão de todo o Direito, veja GRAU, Eros Roberto. Elementos de Direito Econômico. São Paulo: RT, 1981; COMPARATO, Fábio Konder. "O indispensável Direito Econômico". In: Ensaios e Pareceres de Direito Empresarial. Rio de Janeiro: Forense, 1978, pp. 453-472. Confira-se, em especial, as pp. 462, 465 e 471; e BERCOVICI, Gilberto e MASSONETTO, Luís Fernando. "Limites da regulação: esboço para uma crítica metodológica do "novo direito público da economia". Revista de Direito Público da Economia - RDPE, Belo Horizonte, ano 7, n. 25, pp. 137-147, jan./mar. 2009.

${ }^{16}$ RODRIGUES, Nuno Cunha. A Contratação Pública como Instrumento de Política Económica. op.cit., p. 13 , nt. 1 .
} 
o uso do termo "public procurement", bem como "state aquisitions" ou "government purchasing", para designar o mesmo fenômeno ${ }^{17}$. Na Itália, o Codice dei contratti pubblici instituído pelo recente Decreto legislativo 18 aprile 2016, n. 50, incorporando ao plano interno a normativa comunitária de contratações públicas estabelecida pelas Diretivas 2014/23/UE, 2014/24/UE e 2014/25/UE, chama genericamente de "appalti pubblici" os "(...) contratti a titolo oneroso, stipulati per iscritto tra una o più stazioni appaltanti e uno o più operatori economici, aventi per oggetto l'esecuzione di lavori, la fornitura di prodotti e la prestazione di servizi"18. Na França, é corrente o uso da expressão "marchés publics", com o idêntico significado. Em Portugal, a disciplina dada pelo Código de Contratos Públicos (“CCP”) igualmente advém do plano comunitário europeu. Por esse motivo, segundo RODRIGUES, o conceito de "contrato público" torna-se mais amplo do que a noção tradicional de "contrato administrativo", porquanto aquele "(...) abrange todos os contratos celebrados por entes públicos, independentemente de estes serem qualificados como entidades adjudicantes à luz do CCP"19.

A mesma ressalva também pode ser aplicada ao caso brasileiro, como reconhece Thiago Lima BREUs ${ }^{20}$. Neste trabalho, com as expressões "contratações públicas",

\footnotetext{
${ }^{17}$ Para Jean Tirole e Stéphane Saussier, a expressão "public procurement" pode genericamente fazer referência a (i) contratos administrativos tradicionais ("traditional procurement"), voltados a compras, serviços e obras ("works, supplies or services"), (ii) concessões de serviços públicos, ou seja “(...) all contracts (primarily leasing and concession contracts) whereby a public legal entity entrusts the management of a public service for which it is responsible to a public or private delegate -the contractor-in return for a payment that depends largely on the results of the service operation"; e (iii) parcerias público-privadas ("public-private partnerships"), com emprego majoritário em projetos de infraestrutura. Esses três tipos são vistos pelos autores como espécies de um mesmo gênero e, em todos eles, a contratação realizada pela Administração Pública é necessariamente precedida por três questões: (i) "Do it yourself or delegate it?", i.e., decidir entre a execução direta ou indireta do objeto; (ii) "how to outsource it?", ou seja, qual a melhor forma de transferir ao particular o plexo de obrigações relacionado à execução do objeto; e, por fim, (iii) o "design of the contract", desde a seleção dos fornecedores - por meio de um procedimento competitivo ou negociado - até o monitoramento, fiscalização e outros aspectos da gestão contratual. "However, - advertem Saussier e Tirole - it is not so much the decision to outsource as the method of outsourcing -and above all its implementation- that present a problem". SAUSSIER, Stéphane e TIROLE, Jean. "Strengthening the Efficiency of Public Procurement". Les notes du conseil d'analyse économique. Conseil d'analyse économique, $\mathrm{n}^{\circ} 22$, abril.2015. Disponível em: https://www.researchgate.net/publication/275973839_Strengthening_the_Efficiency_of_Public_Procurement . Acesso em 29/06/2015, pp. 2-3.

${ }^{18}$ A semelhança do artigo $3^{\circ}, 1$, "ii" do Codice italiano, transcrito acima, com a definição análoga dada pelo artigo $1^{\circ}$, "5" da Diretiva 2014/23/UE é marcante: " «appalti pubblici»: contratti a titolo oneroso stipulati per iscritto tra uno o più operatori economici e una o più amministrazioni aggiudicatrici aventi per oggetto l'esecuzione di lavori, la fornitura di prodotti o la prestazione di servizi".

${ }^{19}$ RODRIGUES, Nuno Cunha. A Contratação Pública como Instrumento de Política Económica. op.cit., p. 13 , nt. 1.

20 "Como a ideia de contratos públicos é mais identificada como gênero e não como espécie, uma vez que abrange as mais diversas modalidades convencionais, desde contratos de fornecimento, passando pelos contratos da Administração, pelos convênios e até as parcerias público-privadas, esta expressão foi escolhida para designar o objeto de estudo do trabalho: o contrato público, em detrimento da noção mais tradicional no direito administrativo brasileiro - contrato administrativo - que embora mais utilizada na teoria e na
} 
"contratos governamentais" ou "contratos públicos" farei referência de modo amplo a todos os contratos firmados por órgãos ou entidades da Administração Pública, direta e indireta, ainda que não se revistam integralmente de todas as prerrogativas e sujeições que caracterizam o regime jurídico administrativo. Em outras palavras, o "contrato público" é gênero do qual os "contratos administrativos" são espécie, equivalendo à acepção ampla que, em sede doutrinária, foi dada por Maria Sylvia Zanella Di PIETRO à expressão "contratos da Administração" 21 .

Essa escolha terminológica também deixa transparecer um primeiro "corte metodológico" deste estudo: o objeto principal da nossa investigação será o regime das contratações públicas em geral, ou seja, aquele aplicado quotidianamente à aquisição de bens, prestação de serviços e obras para atender às necessidades de órgãos e entes federais, estaduais e municipais. Portanto, será feita referência às leis que disciplinam o regime jurídico das contratações específicas, como as concessões comuns (Lei n ${ }^{\circ} 8.987$, de 13 de fevereiro de 1995), as Parcerias Público-Privadas (Lei n 11.079, de 30 de dezembro de 2004), o Regime Diferenciado de Contratações (Lei $n^{0} 12.462$, de 05 de agosto de 2011 ) e a recente Lei de Responsabilidade das Estatais (Lei $n^{\circ} 13.303$, de 30 de junho de 2016), na medida em que essa providência se mostre necessária para compreender as tendências de flexibilização que esses diplomas tem inspirado no âmbito do próprio regime geral.

Em um segundo "corte metodológico", ressalto que o objeto da pesquisa consiste no poder de compra do Estado no ordenamento jurídico brasileiro. Logo, normas e experiências nacionais constituem as fontes primárias do nosso estudo, que ficará restrito ao exame da legislação federal sobre o tema. O direito comparado será abordado quando se mostrar útil para o melhor entendimento das possibilidades de uso do poder de compra do Estado no cenário nacional, o qual foi largamente influenciado por experiências estrangeiras - em especial, pelo modelo federal de contratações públicas dos Estados Unidos e pelas diretivas da União Europeia sobre o tema.

prática, tradicionalmente possui escopo mais restrito, voltado, essencialmente, para as avenças nas quais se sobressaem os poderes especiais de autoridade e as cláusulas exorbitantes". BREUS, Thiago Lima. O governo por contrato(s) e a concretização de políticas públicas horizontais como mecanismo de justiça distributiva. 263 p. Tese (doutorado). Curitiba: Universidade Federal do Paraná, Setor de Ciências Jurídicas, 2015, p. 241. 21 “A expressão contratos da administração é utilizada, em sentido amplo, para abranger todos os contratos celebrados pela Administração Pública, seja sob regime de direito público, seja sob regime de direito privado. E a expressão contrato administrativo é reservada para designar tão somente os ajustes que a Administração, nessa qualidade, celebra com pessoas físicas ou jurídicas, públicas ou privadas, para a consecução de fins públicos, segundo regime jurídico de direito público”. Maria Sylvia Zanella DI PIETRO. Direito Administrativo. $21^{\mathrm{a}}$ ed. São Paulo: Atlas, 2008, p. 237. 
Por derradeiro, assevero que este é um trabalho jurídico e em razão disso, por uma questão de honestidade intelectual, os cálculos e demonstrações matemáticas apresentados em muitos dos estudos econométricos citados (sobretudo aqueles sobre teoria dos leilões) não foram objeto específico da nossa análise. Procuramos compensar essa circunstância buscando cruzar referências já consolidadas na literatura de public procurement $\mathrm{e}$ artigos escritos por autores de renome internacional, o que minimiza o risco de eventual incompreensão da nossa parte. No mais, destaco que a presente investigação não chamou para si o objetivo de promover uma revisão integral da bibliografia nacional e estrangeira sobre o tema - o que seria absolutamente impraticável na sua circunscrita extensão - mas pretendeu sistematizar as fontes mais relevantes, dentro de recortes específicos, a fim de conduzir o leitor a um panorama abrangente sobre o poder de compra do Estado no Brasil.

Este estudo encontra-se estruturado em três grandes capítulos, além desta introdução e de uma conclusão final.

O primeiro capítulo será dedicado à apresentação e à crítica do que chamamos de “estado da arte” das contratações públicas no Brasil e compõe-se por dois itens.

O primeiro deles busca tecer uma breve reconstrução histórica da legislação brasileira de licitações e contratos, mostrando como se chegou a uma "cultura" aferrada aos ritos, com foco nos processos e pouco compromisso com os resultados das contratações, e que tem como centro gravitacional o formalismo e a rigidez da Lei $n^{\circ} 8.666 / 1993$. A bem da verdade, as fragilidades e defeitos desse marco legal só vem confirmar um diagnóstico que o quotidiano, há muito, já demonstra: não existe uma política estruturada de contratações públicas no Brasil ${ }^{22}$. Nisto não há novidade alguma - o novo, talvez, esteja em reconhecer o erro nas premissas que dão base ao modelo.

$\mathrm{O}$ segundo item investiga mais à fundo a literatura econômica que aponta a complexidade do objeto, as estruturas de mercado, os custos de transação, o oportunismo, as assimetrias informacionais e a incompletude contratual como possíveis desafios àquela premissa, tão cara à legislação brasileira, de que a licitação necessariamente conduz a

${ }^{22}$ Ciro Campos Christo Fernandes defende que as contratações públicas sejam vistas também como uma política pública autônoma, e não somente como instrumento para efetivação e consecução de outras políticas. "As compras públicas tendem a ser encaradas como atividade administrativa que se prestaria a instrumentalizar a consecução de políticas públicas, mas não se problematiza a definição de problemas, o processo decisório e os resultados das mudanças nas políticas" (p. 4). Isso faz com que as principais mudanças no arcabouço normativo das contratações públicas no Brasil sejam influenciadas por escândalos políticos e/ou pressões macroeconômicas momentâneas, que conferem caráter cíclico e pendular à legislação de compras. FERNANDES, Ciro Campos Christo. "A trajetória da construção do arcabouço legal das compras e contratações na administração pública federal brasileira: processo decisório e oportunidade política". In: XIX Congreso Internacional del CLAD sobre la Reforma del Estado y de la Administración Pública. Quito, 11-14 nov./2014. Disponível em: http://repositorio.enap.gov.br/1/1716. Acesso em 06/06/2015. 
Administração Pública à proposta mais vantajosa. Acredito que a compreensão dessas variáveis contribui para demonstrar como a "modelagem" do procedimento e o design do contrato podem ser importantes para atingir os objetivos desejados pelo Poder Público, aproximando as contratações governamentais do método de análise que caracteriza o Direito Econômico.

O segundo capítulo pretende mapear as iniciativas legislativas voltadas à instrumentalização da demanda gerada pelo Estado para a consecução dos chamados objetivos "horizontais", "indiretos", "mediatos" ou "extracontratuais" - não há, como se pode perceber, uma terminologia precisa neste ponto. Interessam-me, de modo especial, as políticas públicas subjacentes às contratações públicas e as formas pelas quais a legislação brasileira cuidou de efetivá-las ${ }^{23}$. Após, investigo os motivos pelos quais a sua aplicação, mesmo quando expressamente autorizada em lei, é tão pouco frequente no quotidiano da Administração Pública no Brasil, sobretudo diante da jurisprudência restritiva que o Supremo Tribunal Federal firmou sobre o tema.

Por fim, o terceiro capítulo aborda a "modelagem" das licitações e contratos para atingir, a um só turno, objetivos contratuais e extracontratuais. Este é o campo, creio, em que devem ser buscados os novos parâmetros para o poder de compra do Estado. Identificamos dois eixos para nossa análise, sendo que cada qual corresponderá a um item diferente na estrutura do trabalho.

O primeiro diz respeito à intensidade com que o procedimento deve ser exposto à concorrência, aspecto que guarda estreita relação, à luz da teoria dos leilões, com as estruturas de mercado e com o grau de complexidade do objeto licitado. Defendo que o design das licitações e dos contratos seja explorado pelo Estado como instrumento a fim de canalizar a demanda gerada pelo setor público para aumentar a qualidade dos bens e dos serviços contratados pela Administração Pública, e, ainda, atingir os objetivos horizontais considerados mais relevantes à luz do caso concreto.

O segundo eixo trata dos reflexos dessa "modelagem” para a prevenção do conluio, fraudes e práticas de corrupção em licitações. Aqui, especial ênfase será dada à formação de carteis e à análise dos efeitos pró e anticolusivos decorrentes de fatores estruturais e provenientes do design do procedimento licitatório, de outro. Para tanto, a literatura

\footnotetext{
${ }^{23}$ Para elaborar esse elenco, restringi o objeto de nossa investigação às leis e atos normativos editados pela União, a quem foi atribuída, nos termos do artigo 22, inciso XXVII, da Constituição Federal, a competência privativa para legislar sobre "normas gerais de licitação e contratação". Por conseguinte, iniciativas semelhantes tomadas por Estados, Municípios e pelo Distrito Federal aparecerão apenas por via reflexa na pesquisa jurisprudencial que integra o mesmo capítulo.
} 
econômica será revisitada com o intuito de colher, no direito comparado, alguns exemplos de como o poder de compra do Estado pode ser empregado de modo muito eficaz para combater a corrupção - tema que, como visto, assume posição central na legislação brasileira. Temos ciência de que a implementação prática de grande parte dessas medidas requer alterações no marco legal que, ao que parece, não constituem prioridade na agenda política. Entretanto, esperamos conseguir indicar alguma direção a ser seguida caso se pretenda trilhar o caminho rumo à revalorização das licitações e das contratações públicas no Brasil. 


\section{CONCLUSÕES}

Martin Loughlin, Professor de Direito Público da London School of Economics, inicia o seu The idea of Public law advertindo o leitor que o trabalho monográfico ironicamente não resulta em uma compreensão do objeto pesquisado, mas sim em um ainda não compreendido ${ }^{1}$. Na medida em que me aproximo das linhas finais deste trabalho, percebo que LOUGHLIN não poderia estar mais correto: mais do que apresentar uma compreensão hermética e abrangente acerca do tema, o presente estudo pretendeu lançar algumas luzes sobre o que ainda não é bem compreendido no vasto universo das contratações celebradas pelo Poder Público no Brasil.

Minha investigação partiu de um problema: naquele momento inicial, eu buscava respostas para uma contradição entre a rigidez e o formalismo da legislação de licitações e a ocorrência, tão difundida quanto desonrosa para a Administração Pública brasileira, de fraudes e corrupção envolvendo procedimentos licitatórios. Somem-se a esse cenário, ainda, a extenuante burocracia, à morosidade e à péssima qualidade dos bens e serviços contratados pelo Estado para desenvolver suas atividades-meio e atividades-fim. Talvez, esse descompasso possa ser explicado pelo fato de que as obras jurídicas sobre o tema geralmente se limitam a tecer uma exposição dogmática dos institutos e normas vigentes acerca da matéria, em uma exegese excessivamente preocupada em fornecer subsídios à prática das licitações no Brasil. Ao deparar-se com esses manuais e comentários à Lei nº 8.666/1993 e a outros diplomas legais, acredito que o leitor seja deixado com a errônea impressão de que, tão logo concluído o certame licitatório, adjudicado o objeto e assinado o contrato, os problemas e as dúvidas jurídicas desaparecem, de tão diminuta que é a preocupação com a qualidade e a gestão contratual. Mas a realidade das contratações públicas é profícua em ilustrar que isso não é verdade, revelando um imenso plexo de desafios que desmentem, de forma veemente, essa falsa noção inicial.

Como afirmam MedeIRos e FiUZA, é necessário “(...) pensar fora da caixa” para questionar os pressupostos que norteiam as licitações e os contratos públicos no Brasil ${ }^{2}$. Acolhendo a sugestão dos autores, ousamos ir além da doutrina tradicional - sujeitando-nos a todos os riscos que essa escolha metodologicamente implica - para refletir sobre a forma

\footnotetext{
${ }^{1}$ LOUGHLIN, Martin. The Idea of Public Law. Oxford: Oxford University Press, 2003, pp. V-VIII.

${ }^{2}$ FIUZA, Eduardo Pedral Sampaio e MEDEIROS, Bernardo Abreu de. A agenda perdida das compras públicas: rumo a uma reforma abrangente da lei de licitações e do arcabouço institucional. Texto para discussão no 1990. Rio de Janeiro: Instituto de Pesquisa Econômica Aplicada (IPEA), 2014, p. 15.
} 
pela qual o Estado brasileiro exerce o seu nada desprezível poder de compra. Para tanto, ao percorrer o itinerário proposto na "Introdução" deste trabalho, busquei dar às licitações e às contratações públicas um enfoque diferente daquele que é dado ao mesmo tema pelo Direito Administrativo. Em meio à fluida intersecção entre o Direito e a Economia, enxergar as contratações públicas sob as lentes do Direito Econômico implicou na descoberta de um instrumento poderoso pelo qual o Poder Público articula a sua demanda por bens e serviços para atender aos objetivos que entender mais relevantes em cada caso concreto, tanto no plano contratual quanto no plano extracontratual.

No primeiro capítulo, reconstruímos a trajetória da legislação brasileira de licitações e contratos para mostrar como essa temática paulatinamente se desloca do campo das Finanças Públicas para a seara do Direito Administrativo. Nesse percurso, foi possível verificar a alternância de "gestão" e "controle" como os vetores prevalecentes em cada tentativa de reforma do marco legal, bem como uma transição lenta, mas gradual, de uma legislação minimalista, centrada no Código de Contabilidade de 1922, para um modelo maximalista do qual a Lei $\mathrm{n}^{\circ}$ 8.666/1993 constitui, até hoje, a maior expressão. É interessante notar como muitas dessas alterações estavam inseridas em uma agenda mais ampla de reforma administrativa (o Decreto-Lei $n^{\circ}$ 200/1967 e o Decreto-Lei ${ }^{\circ}$ 2.300/2986, por exemplo) ou, então, foram apresentadas pelo governo como medidas ancilares para o controle do gasto público e o ajustamento fiscal do Estado brasileiro, tais como a centralização e a padronização pretendidas por José Maria Whitaker nas reformas da década de 1930 e, mais recentemente, a universalização da modalidade pregão para encorajar o atendimento à Lei de Responsabilidade Fiscal, no início dos anos 2000.

Revisitar o processo legislativo que levou à vigente Lei de Licitações contribuiu muito para explicar a ratio legis que aflora nas entrelinhas do texto legal: a regulação intensa, detalhada e minudente, somada à pretensão universalizante de aplicar-se a todo o conjunto heterogêneo das contratações públicas no Brasil, buscava vincular ao máximo o gestor e restringir sua capacidade de escolha com o intuito de moralizar a Administração Pública e livrar-lhe da chaga da corrupção. No entanto, comemoradas mais de duas décadas de sua vigência, a opção legislativa não teve êxito em produzir a consequência almejada, gerando um engessamento e uma rigidez acentuada que ostentam efeitos negativos sob o prisma da gestão pública. Desde então, parece que o consenso está justamente em "fugir" da Lei n ${ }^{\circ}$ 8.666/1993 - notadamente, por meio da proliferação de "válvulas de escape" ao rigor da lei geral e pela fragmentação do regime unitário em diversos regimes paralelos para contratações específicas. 
Atualmente, o "estado da arte" das licitações no Brasil caracteriza-se pela existência de uma forte cultura de punição a desvios e de apego a formalidades que convive com um certo desinteresse na eficiência dos procedimentos licitatórios e na qualidade dos bens e serviços contratados pelo Poder Público. Focar em processos ao invés de resultados, como alerta MotTA, propicia a adoção de comportamentos defensivos por parte dos gestores de compras e agrava ainda mais o já tão vultoso desperdício passivo ${ }^{3}$. Outrossim, a existência de um trade off entre a complexidade do objeto e o grau de concorrência a que a adjudicação de um contrato deve estar sujeita evidencia que o sucesso da licitação enquanto método de escolha da proposta mais vantajosa não é garantido. É por isso que a realização de um certame licitatório nem sempre é o melhor caminho a seguir, como inclusive reconhecem a FAR, nos EUA, e os procedimentos negociados das diretivas comunitárias, no âmbito da União Europeia. A rigidez da contratação pública torna-a mais exposta ao problema de agência, ao conluio e à captura, sobretudo em mercados oligopolizados. Logo, conferir ao contratante algum grau de flexibilidade para definir o design da licitação e do contrato é indispensável para criar uma estrutura de incentivos que lide adequadamente com esses fatores, reduzindo custos de transação e evitando o oportunismo por parte de licitantes, terceiros e contratados.

Nesse contexto atual, em que os próprios objetivos contratuais, diretos e imediatos das contratações públicas já estão relegados a segundo plano, parece-me evidente que eventuais tentativas de ir além, com vistas a empregar o poder de compra do Estado para a consecução de objetivos extracontratuais, indiretos e mediatos, estejam fadadas ao fracasso. No segundo capítulo, analisei a incorporação de alguns objetivos horizontais pela legislação federal brasileira e cheguei à conclusão de que, a despeito dos avanços recentes nesse sentido, o emprego das contratações públicas como instrumento para atingir finalidades que ultrapassem as fronteiras do contrato celebrado ainda é muito incipiente, sendo rara a sua aplicação no dia-a-dia da Administração Pública. Afinal, os gestores de compras normalmente resistem em aplicar preferências ou critérios que possam vir a ser interpretados pelos órgãos de controle como eventuais lesões à competitividade ou à economicidade. Diante de um cenário como esse, defendo que a melhor solução para esse problema não está, absolutamente, em tornar obrigatória a aplicação desses objetivos horizontais, mas sim em

\footnotetext{
${ }^{3}$ MOTTA, Alexandre Ribeiro. O combate ao desperdício no gasto público: uma reflexão baseada na comparação entre os sistemas de compra privado, público federal norte-americano e brasileiro. 2010. $189 \mathrm{p}$. Dissertação (Mestrado) - Instituto de Economia (IE), Universidade Estadual de Campinas, Campinas, 2010, p. 157.
} 
reverter o formalismo dessa nossa "cultura" de licitações, a qual leva os gestores a voluntariamente querer afastar o que a legislação já lhes autoriza expressamente. Não olvidamos que esse processo seja difícil e moroso. Mas, sem ele, é bastante provável que o apego excessivo ao menor preço - chancelado, inclusive, pela jurisprudência do Supremo Tribunal Federal sobre o tema - continue a atravancar a possibilidade de que o Estado assuma, ainda que parcialmente, os custos de produtos e serviços que gerem externalidades positivas entendidas como desejáveis, em dado momento, sob os pontos de vista social, ambiental ou econômico.

O terceiro capítulo foi dedicado ao cerne do presente estudo e àquele que, talvez, seja o meu argumento mais recorrente e importante. Ao longo de todo este trabalho defendi que o Poder Público tenha flexibilidade para escolher a melhor maneira de licitar e de contratar em cada caso concreto, recusando a definição apriorística, ex ante, do procedimento de adjudicação a ser empregado - o que compreende, vale lembrar, diversos tipos de leilão ou a opção por negociações diretas - e do modelo de contrato mais indicado para reger a relação entre as partes pública e privada da avença. Ao fazê-lo, cumpre esclarecer que não estou a advogar contra as licitações nem a pleitear o abrandamento do dever constitucional de licitar. Muito pelo contrário: não é o porquê, mas sim o como licitar que deve ser repensado para revalorizar o instituto a partir de uma compreensão mais profunda das suas potencialidades. Nessa linha, o trade off entre o grau de concorrência e a complexidade do objeto, associado àquele existente entre riscos e incentivos, devem servir como balizas para que o Estado decida qual o nível de competitividade a que deseja submeter a contratação pública, seja para aumentar o seu retorno enquanto contratante (o "value for money"), seja para garantir a oferta de altos níveis de qualidade contratável e não contratável por parte do particular contratado. Este é o caminho mais indicado para reduzir o desperdício passivo, que corresponde à maior parte do mau uso do dinheiro público, bem como para direcionar a demanda gerada pelo setor público os objetivos horizontais, indiretos e mediatos que seguem, em larga medida, não realizados em nosso país.

No mesmo sentido, a "modelagem" da licitação e do contrato pode ser essencial para construir uma estrutura de incentivos e sanções que dificulte a coordenação e o enforcement de cartéis, mitigando eventuais efeitos colusivos advindos da complexidade do objeto, da concentração de mercado e de outros fatores estruturais. Tenho consciência de que a preocupação com o desperdício ativo ocupa um papel central para a legislação brasileira e, por isso, estou seguro de que nossa proposta busca reconciliar a prática das licitações e contratações públicas com a sua vocação original. Note-se, porém, que essa visão se 
contrapõe frontalmente àquela, muito presente durante a tramitação do projeto que se converteu na Lei $\mathrm{n}^{\mathrm{o}}$ 8.666/1993, que entende necessário limitar ao máximo a discricionariedade do gestor público para impedir a ocorrência de conluio e fraudes em licitações e contratos. Ora, minha crítica volta-se à hipocrisia desse argumento. Hoje, o formalismo da legislação brasileira funciona ao mesmo tempo como desculpa para a incompetência e como um aval para o cometimento de veladas ilegalidades que, não raro, passam incólumes pelas auditorias dos órgãos de controle interno e externo ${ }^{4}$. Tenho consciência da força dessa afirmação, mas estou convicto de que suprimir do Poder Público a escolha de como licitar e contratar não compensa os malefícios desse efeito colateral nefasto, que transforma a licitação em um deprimente "teatro de sombras". Quando o risco de colusão é significativo, o design do procedimento e do próprio contrato devem ser adaptados para impedir a captura da Administração e desestimular eventuais comportamentos rent-seeking. E, reconhecida a impossibilidade de uma definição a priori, essas circunstâncias devem ser analisadas e sopesadas à luz de cada situação concreta.

Essas são as principais conclusões a que cheguei ao longo de minha pesquisa sobre o poder de compra do Estado no Brasil. Entretanto, retomando a expressão de LOUGHLIN, devo reconhecer um tópico "ainda não compreendido" sobre o tema, mas que pode abrir caminho para pesquisas e investigações futuras. Quais devem ser as finalidades das licitações e das contratações públicas? Quais devem prevalecer e quais devem sucumbir quando colidirem no caso concreto? Que critérios o ordenamento jurídico deve fornecer para solucionar esses conflitos sem frustrar os designíos do Estado-comprador? Não me propus, neste trabalho, a fornecer respostas a essas indagações. Mas Khi V. THAI aponta uma possível linha de resposta ao propor uma análise institucionalista das contratações públicas, buscando compreendê-las enquanto um sistema constituído por diversos elementos ${ }^{5-6}$.

\footnotetext{
${ }^{4}$ É bastante frequente a existência de contratos celebrados pela Administração Pública que, não obstante apresentem todos os relatórios de medições e termos de recebimento assinados, jamais foram executados. Isso, infelizmente, constitui prática corriqueira em contratos de abastecimento de veículos e prestação de serviços de TI, bem como outros objetos consumíveis ou que não deixem vestígios verificáveis em auditorias e verificações in loco.

${ }^{5}$ THAI, Khi V. "Public Procurement re-examined". Journal of Public Procurement, volume 1, issue 1, 2001, pp. 09-50.

${ }^{6}$ Essa visão sistêmica, segundo Thai, permite comparar a dinâmica das contratações públicas estudo do funcionamento de um carro: "After being assembled, the public procurement system is similar to a car. The vehicular performance of a car depends on many factors, including the quality of its parts, engineering design, road and traffic conditions, and its driver. Similarly, the vehicular performance of a public procurement system depends on its elements, (...). As these elements vary among governmental entities, it is impossible to come up with a one-size-fits-all public procurement system as the performance of a system depends not only on its elements but also on its chemistry" THAI, Khi V. "Public Procurement re-examined", op. cit., p. 41.
} 
Partindo das contribuições de Elionor OSTROM para a Nova Economia Institucional ${ }^{7}$, THAI afirma que o sistema de contratações públicas influencia e ao mesmo tempo é influenciado por um environment complexo, formado por forças políticas, sociais e econômicas, nos planos interno e internacional ${ }^{8}$. Por isso, o sistema é dinâmico e sempre está em busca de um equilíbrio ótimo entre os "procurement goals", noção análoga ao que viemos chamando de objetivos diretos ou contratuais, e os "non-procurement goals" que, grosso modo, correspondem aos objetivos indiretos ou extracontratuais. Segundo THAI, “(...) procurement goals normally include quality, timeliness, cost (more than just the price), minimizing business, financial and technical risks, maximizing competition, and maintaining integrity”, ao passo que “(...) non-procurement goals normally include economic goals preferring domestic or local firms), environment protection or green procurement (promoting the use of recycled goods), social goals (assisting minority and woman-owned business concerns), and international relations goals" ${ }^{\prime 9}$. Como não é possível estabelecer ex ante uma hierarquia entre "procurement goals" e "non-procurement goals", objetivos diversos como "aumentar a qualidade do objeto contratado", "impedir o oportunismo e práticas de corrupção" e "tutelar o meio ambiente" assumem igual importância dentro do sistema, motivo pelo qual sua primazia ou secundariedade só poderá ser conhecida à luz do caso concreto, segundo o que for mais relevante para o Poder Público na ocasião.

Pessoalmente, acredito que um sistema de contratações públicas deve lidar com pelo menos três questões fundamentais. A primeira trata do grau de intensidade da regulação estatal exercida sobre os procedimentos de adjudicação, a fim de saber se a legislação seguirá o paradigma do maximalismo, na esteira da Lei $\mathrm{n}^{\circ} 8.666 / 1993$, definindo aprioristicamente as minúcias e os detalhes de cada tipo de procedimento; ou se fará a opção

\footnotetext{
7 Thai adota a acepção de "instituições" cunhada por Elionor Ostrom, ou seja, não como sinônimo de "organização", mas sim para fazer referência às regras, normas e estratégias adotadas por indivíduos que interagem com organizações. Assim, "(...) institutions are invisible because they are 'fundamentally shared concepts', 'exist in minds of the participants', and 'sometimes are shared as implicit knowledge rather than in an explicit and written form'". THAI, Khi V. "Public Procurement re-examined", op. cit., p. 38. Sobre a contribuição de Ostrom, confira: OSTROM, Elinor. Governing the commons - the evolution of institutions for collective action. Cambridge (UK): Cambridge University Press, 1990; OSTROM, Elinor e SCHLAGER, Edella. "Property-rights regimes and natural resources: a conceptual analysis", Land Economics, vol. 68, n. 3, ago./1992, pp. 249-262; e OSTROM, Elinor. Understanding Institutional Diversity. Princeton: Princeton University Press, 2005.

${ }^{8}$ Um exemplo mencionado por Thai refere-se à compra bilionária, pelo Governo da Coréia do Sul, de caças de combate no início dos anos 2000. "The South Korean government must choose between one of the four bidders-Boeing of the U.S., Russia's Rosvoorouzhenie, the European consortium Eurofighter and France's Dassault Aviation". O lobby proveniente da política externa de cada um desses países fez-se sentir ao longo de todo o processo licitatório, que incluiu até mesmo visitas de Chefes de Estado para defender os interesses de cada player na aquisição multibilionária. THAI, Khi V. "Public Procurement re-examined", op. cit., p. 37.

9 THAI, Khi V. "Public Procurement re-examined", op. cit., p. 27, ambos os trechos.
} 
pelo minimalismo, fixando na lei apenas as diretrizes e linhas mestras que os regulamentos, instruções normativas e outros atos infralegais deverão observar ao estabelecer a disciplina específica para a contratação de cada tipo de objeto, no caminho que timidamente começou a ser trilhado, no Brasil, pelo pregão e pelo $\mathrm{RDC}^{10}$. A segunda questão guarda relação direta com a primeira e diz respeito ao grau de discricionariedade do agente público para a tomada das decisões principais do processo de sourcing, desde o dilema "make or buy" até o design final da licitação e do contrato (se, o quê, como e quando contratar). Por fim, em terceiro lugar, o grau de centralização ou descentralização dos órgãos a quem são atribuídas funções de licitar e contratar, que corresponde ao aspecto organizacional do sistema de contratações públicas no âmbito do Estado-comprador.

A delimitação desses três pilares ainda está em aberto e depende de uma reflexão mais aprofundada. Até porque, como dito, a estruturação de um sistema de contratações públicas sob o viés institucionalista de THAI merece uma investigação específica no futuro. Por ora, questionar os elementos que compõem esse sistema desponta como um importante ponto conexo à ampla rediscussão que buscamos realizar, neste trabalho, sobre os pressupostos em que se baseia a legislação de licitações e contratações públicas no Brasil. A superação do modelo legal vigente, o qual criticamos pela sua excessiva rigidez e acentuado formalismo, é apenas um primeiro passo nesse sentido. Acredito firmemente que a "modelagem" do procedimento licitatório e do contrato para aumentar ou diminuir a concorrência, de um lado, ou para inibir a corrupção, de outro, representa um campo relativamente inexplorado e com imenso potencial. E é por esse motivo que dedicamos este estudo, elaborado sob o viés do Direito Econômico, ao mapeamento dessas várias possibilidades. Enquanto as licitações forem pensadas tão somente como tema de Direito Administrativo e não como instrumento fundamental para a regulação da demanda gerada pelo setor público, muito pouco se terá avançado no atingimento dos diversos objetivos buscados pela Administração Pública nos ajustes que celebra. São esses, a meu ver, os novos parâmetros que devem orientar o exercício do poder de compra do Estado no Brasil.

\footnotetext{
${ }^{10}$ Vale lembrar que a Lei n ${ }^{\mathrm{o}} 12.462$, de 04 de agosto de 2011 remeteu a definição de diversos temas importantes ao Decreto $n^{\circ} 7.581$, de 11 de outubro de 2011, que regulamenta o RDC. Mas esse tipo de deslegalização ainda é tímida quando comparada àquela que existe em diversos países europeus, onde as agências e centrais de compras editam instruções normativas aplicáveis especificamente à contratação de tipos específicos de bens e serviços.
} 



\section{BIBLIOGRAFIA}

ABRAMO, Cláudio W. e CAPOBIANCO, Eduardo R. "Licitaciones y contratos públicos. El caso de Brasil”. Nueva sociedad, v. 194, p. 69-90, 2004.

ABREU, Mateus Barbosa Gomes; LIMBERGER, Têmis; TEIXEIRA, Anderson Vichinkeski; "Contratos administrativos e gestão pública - Proposições a partir de estudos de casos na Administração Pública federal indireta". Revista de Direito Administrativo \& Constitucional. Belo Horizonte: Fórum, ano 14, n. 58, out./dez. 2014, pp. 155-176.

ACCORSI, Antonio Carlos. Estado e grupos econômicos. A política de expansão rodoviária no Brasil a partir de 1930. 171 p. Dissertação (Mestrado). São Paulo: EAESP/FGV, 1996.

AKERLOF, George. "The Market for Lemons: Quality Uncertainty and the Market Mechanism”. Quarterly Journal of Economics, v. 84, n. 3, ago/1970.

ALBANO, G.L.; BUCCIROSSI, P.; SPAGNOLO, G.; ZANZA; M. "Preventing collusion in procurement". In: DIMITRI, N.; PIGA, G.; SPAGNOLO, G. (Ed.). Handbook of procurement. Cambridge (UK): Cambridge University Press, 2006, pp. 347-380.

.; DIMITIRI, N.; PERRIGNE, I.; PIGA, G.; "Fostering Participation". In: DIMITRI, N.; PIGA, G.; SPAGNOLO, G. (Ed.). Handbook of procurement. Cambridge (UK): Cambridge University Press, 2006, pp. 267-292

; DINI, F.; IOSSA, E.; SPAGNOLO, G.; "Procurement contracting strategies". In: DIMITRI, N.; PIGA, G.; SPAGNOLO, G. (Ed.). Handbook of procurement. Cambridge (UK): Cambridge University Press, 2006, pp. 82-120

ALÉM, Ana Cláudia e GIAMBIAGI, Fábio. Finanças Públicas: teoria e prática no Brasil. $4^{\mathrm{a}}$ ed. Rio de Janeiro: Elsevier, 2011.

ALESSIO, Nelson Luiz Nouvel. A Política Pública de Licitações no Município de São Paulo entre 1991 e 1994: mecanismo de facilitação ou de restrição da competição entre potenciais fornecedores do poder público municipal? 143 p. Dissertação (Mestrado). São Paulo: $\mathrm{EAESP} / \mathrm{FGV}, 1998$.

ARAÚJO, Paula Mara Costa de e JESUS, Renata Gomes de. "Processo licitatório tipo menor preço e eficiência em compras públicas: um estudo de caso". In: XXXVII Encontro da Associação Nacional de Pós-Graduação e Pesquisa em Administração (ANPAD). Rio de Janeiro: ANPAD, set/2013. Disponível em: http://www.fucape.br/_public/ producao_cientifica/2/APB411-\%20Paula\%20Mara \%20Costa\%20de \%20 Araujo. pdf. Acesso em 11/05/2016.

ARROWSMITH, Sue, "A taxonomy of horizontal policies in public procurement", in: ARROWSMITH, Sue e KUNZLIK, Peter (orgs). Social and environmental policies in EC procurement law. New Directives and New Directions. Cambridge (UK): Cambridge University Press, 2009, pp. 108-146. 
. "Application of the EC Treaty and Directives to horizontal policies: a critical view", in ARROWSMITH, Sue e KUNZLIK, Peter (orgs). Social and environmental policies in EC procurement law, Cambridge University Press, 2009, pp. 147-248.

ASSIS, Lucas Rocha Soares de e SCHMIDT, Flávia de Holanda.; "O Estado como cliente: características das firmas industriais fornecedoras do governo". Radar: tecnologia, produção e comércio exterior. Brasília: Instituto de Pesquisa Econômica Aplicada (IPEA), Vol. 1, n. 17, abr/2009, pp. 09-20.

.; SCHMIDT, Flávia de Holanda. A dinâmica recente do setor de defesa no Brasil: análise das características e do envolvimento das firmas contratadas. Texto para

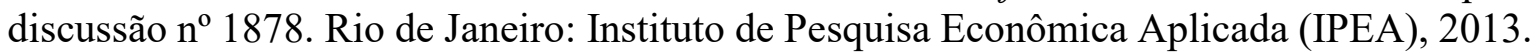

BAJARI, Patrick e TADELIS, Steven. "Incentives Versus Transaction Costs: A Theory of Procurement Contracts". RAND Journal of Economics, n. 32, 2001, pp. 387-407.

.; HOUGHTON, Stephanie; TADELIS, Steven. Bidding for incomplete contracts: an empirical analysis. Cambridge (MA): National Bureau of Economic Research, 2006 (NBER Working Paper, n. 12.051).

.; McMILLAN, J.; TADELIS, S. "Auctions versus negotiations in procurement: an empirical analysis". Journal of Law, Economics and Organization, v. 25, n. 2, 2008, pp. 372-399. (NBER Working Paper, n. 9.757)

. e LEWIS, Gregory; "Procurement Contracting With Time Incentives: Theory and Evidence". The Quarterly Journal of Economics, Oxford University Press, vol. 126 (3), 2011, pp. 1173-1211. (NBER Working Paper, n.14855)

BANCO MUNDIAL. Brazil - Country procurement assessment report. Washington (DC): World Bank, 2004. Disponível em: http://documents.worldbank.org/curated/en/ 2004/03/3575914/brazil-country-procurement-assessment-report.Acesso em 11/05/2015.

BANDIERA, Oriana; PRAT, Andrea; VALLETTI, Tommaso. "Active and Passive Waste in Government Spending: Evidence from a policy experiment". CEIS (Centre for Economic and International Studies) Tor Vergata (Research Paper Series). Vol. 6, Issue 4, n.. 115, 2008. Posteriormente publicado como The Economics of Public Procurement, American Economic Review, pp.1278-1308, 2009. Disponível em: http://ssrn.com/abstract=1115339. Acesso em 15/02/2015.

BARBOSA, Denis Borges. "Licitação como instrumento de incentivo à inovação: o impacto da Lei n. 12.349/2010". Boletim de Licitações e Contratos, São Paulo, v. 27, n. 1, p. 1-15, jan. 2014. Disponível em: http://dspace/xmlui/bitstream/item/9417 /geicIC_FRM_0000_pdf.pdf?sequence=1. Acesso em 13/02/2015.

BERCOVICI, Gilberto; ANDRADE, José Maria Arruda de; MASSONETTO, Luís F. "Reforma do Estado, Prestação de Serviços Públicos, Contribuições Especiais e Federalismo". Revista do Instituto de Pesquisas e Estudos, Bauru, v. 45, 2006, pp. 173-179.

. e MASSONETTO, Luís Fernando. "A Constituição Dirigente Invertida: A Blindagem da Constituição Financeira e a Agonia da Constituição Econômica". Separata do 
Boletim de Ciências Econômicas - Universidade de Coimbra, Coimbra, Portugal, v. XLIX, 2006.

. e MASSONETTO, Luis Fernando. "Limites da regulação: esboço para uma crítica metodológica do "novo direito público da economia"'. Revista de Direito Público da Economia - RDPE, Belo Horizonte, ano 7, n. 25, jan./mar. 2009, pp. 137-147.

. "O Ainda Indispensável Direito Econômico". In: BENEVIDES, M. V. de M.; BERCOVICI, G.; MELO, C. (Org.). Direitos Humanos, Democracia e República: Homenagem a Fábio Konder Comparato. São Paulo: Quartier Latin, 2009, pp. 503-519.

. "A Atuação do Estado Brasileiro no Domínio Econômico". In: COSTA PINTO, E.; CARDOSO JR, J. C.; LINHARES, P. de T.. (Org.). Estado, Instituições e Democracia: Desenvolvimento. Brasília: IPEA, 2010, v. 3, pp. 473-503.

. "O Direito Constitucional Passa, o Direito Administrativo Permanece": A Persistência da Estrutura Administrativa de 1967. In: TELES, E.; SAFATLE, V. (Org.). $O$ Que Resta da Ditadura: A Exceção Brasileira. São Paulo: Boitempo Editorial, 2010, pp. 7790.

. "Política Econômica e Direito Econômico". Pensar (UNIFOR), v. 16,

2011.

. "Petrobras - Monopólio estatal e política concorrencial". Revista Fórum

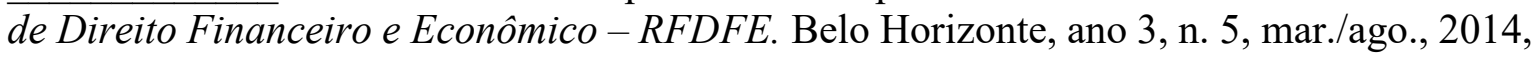
pp. 135-148.

BIM, Eduardo Fortunato. "Considerações sobre a juridicidade e os limites da licitação sustentável”. In: BARKI, Teresa Villac Pinheiro e SANTOS, Murillo Giordan (Coord.). Licitações e contratações públicas sustentáveis. Belo Horizonte: Fórum, 2011.

BRASIL. Ministério da Administração federal e da Reforma do Estado (MARE). Plano Diretor da Reforma do Aparelho do Estado. Brasília: Presidência da República, Imprensa Oficial, nov./1995. Disponível em: http://www.bresserpereira.org.br/ Documents/ MARE/ PlanoDiretor/ plano diretor.pdf. Acesso em 15/10/2015.

.. Ministério da Justiça. Análise dos aspectos concorrenciais do PLC $n^{o}$ 32/2007. Brasília: SDE/CGCP, 2008.

. Brasil 2022: trabalhos preparatórios. Brasil: Presidência da República, Secretaria de Assuntos Estratégicos - SAE, 2011.

. Departamento de Proteção e Defesa Econômica da Secretaria de Direito Econômico do Ministério da Justiça. Combate a cartéis em licitações: guia prático para pregoeiros e membros de comissão de licitação. Disponível em: http://www.4icfex.eb.mil.br/index.php?option=com_content\&view=article\&id=118:comba te- a-carteis- em-licitacoes\&catid=26:atencao\&Itemid=21. Acesso em 23/11/2016.

BRESSER-PEREIRA, Luiz Carlos. "A reforma gerencial do Estado de 1995". Revista de Administração Pública, n. 34, 4, julho/2000, pp. 55-72. 
BREUS, Thiago Lima. O governo por contrato(s) e a concretização de políticas públicas horizontais como mecanismo de justiça distributiva. 263 p. Tese (doutorado). Curitiba: Universidade Federal do Paraná, Setor de Ciências Jurídicas, 2015.

BULOW, Jeremy e KLEMPERER, Paul. "Auctions versus Negotiations" The American Economic Review, Vol. 86, nº 1, mar/1996, pp. 180-194.

CAMPOS, Francisco. "Concorrência pública - Contrato administrativo - Registro no Tribunal de Contas - Autarquia - E.F. Santos a Jundiahy”. Revista de Direito Administrativo, Rio de Janeiro, v. 63, p. 338-344, jan. 1961.

CARPINETI, Laura; PIGA, Gustavo; ZANZA, Matteo. "The variety of procurement practice: evidence from public procurement”. In: DIMITRI, N.; PIGA, G.; SPAGNOLO, G. (Ed.). Handbook of procurement. Cambridge (UK): Cambridge University Press, 2006, pp. 14-44.

CHONG, Eshien; STAROPOLI, Carine; YVRANDE-BILLON, Anne. "Auction versus Negotiation in Public Procurement: Looking for Empirical Evidence". In: BROUSSEAU, E.; GLACHANT, J-M. The Manufacturing Markets, Legal, Political and Economic Dynamics, Cambridge (UK): Cambridge University Press, 2014, pp. 120-142. Versão eletrônica disponível em: https://hal.archives-ouvertes.fr/hal-00512813. Acesso em 22/08/2016.

CICOGNA, Cristina. "L'outsourcing delle funzioni strumentali della Pubblica Amministrazione". In: FIORENTINO, Luigi (Org.). Lo stato compratore. L'acquisto di beni e servizi nelle publiche amministrazioni. Bologna: Il Mulino, 2007, pp. 25-45

COASE, Ronald H. "The nature of the firm". Economica. New Series, Vol. 4, Issue 16, nov./1937, pp. 386-405.

. "The problem of social cost". The Journal of Political Economy. Chicago: University of Chicago, Vol. 3, out./1960, pp. 1-44.

COMPARATO, Fábio Konder. "O indispensável Direito Econômico". In: Ensaios e Pareceres de Direito Empresarial. Rio de Janeiro: Forense, 1978, pp. 453-472.

COVIELLO, Decio e GAGLIARDUCCI, Stefano, "Building political collusion: evidence from procurement auctions", Institute for the Study of Labor (IZA), IZA Discussion Papers no. 4939, Bonn, 2010.

CRAMTON, Peter; SCHWARTZ, Jesse A.; "Collusive Bidding: Lessons from the FCC Spectrum Auctions". Journal of Regulatory Economics, n 17, mai./2000, pp. 229-252.

CRUZ, Paulo Roberto Davidoff Chagas. "Capitais externos e o financiamento de longo prazo no Brasil”. In: SUZIGAN, Wilson e SZMRECSÁNYI, Tamás (Orgs,) História Econômica do Brasil Contemporâneo. São Paulo: Ed. HUCITEC, 1997.

CYMBALISTA, Tatiana Matiello; ZAGO, Marina Fontão. RODRIGUES, Fernanda Esbizaro, "O poder de compra estatal e a margem de preferência para produtos e serviços 
nacionais introduzida na Lei de Licitações". Revista de Direito Público da Economia RDPE. Belo Horizonte, ano 9, n. 35, jul./set. 2011, pp. 143-175.

DI PIETRO, Maria Sylvia Zanella. Direito Administrativo. 21 ${ }^{\text {a }}$ ed. São Paulo: Atlas, 2008.

DIMITRI, Nicola; DINI, Federico; PIGA, Gustavo; "When should procurement be centralized?" In: DIMITRI, N.; PIGA, G.; SPAGNOLO, G. (Ed.). Handbook of procurement. Cambridge (UK): Cambridge University Press, 2006, pp. 47-81.

DOTTI, Marinês Restelatto e PEREIRA JÚNIOR, Jessé Torres. Politicas Públicas nas Licitações e Contratações Administrativas. 2a ed. Belo Horizonte: Fórum, 2012.

DRAIBE, Sonia Miriam. Rumos e Metamorfoses - Estado e Industrialização no Brasil: 1930/1980. 2. ed. Rio de Janeiro: Paz e Terra, 1985. v. 1.

EDLER, Jakob. GEORGHIOU, Luke. "Public procurement and innovation - resurrecting the demand side". Research Policy. n. 36, 2007, pp. 949-963.

EDQUIST, Charles e HOMMEN, Leif "Public Technology Procurement and Innovation Theory”. In: EDQUIST, C.; HOMMEN, L.; TSIPOURI, L. (Eds.), Public technology procurement and innovation. Boston/Dordrecht/London: Kluwer Academic Publishers, 2000 .

FERNANDES, Ciro Campos Christo. Política de compras e contratações: trajetória e mudanças na administração pública federal brasileira. 285p. Tese (Doutorado). Rio de Janeiro: Escola Brasileira de Administração Pública e de Empresas/FGV, 2010.

. "A trajetória da construção do arcabouço legal das compras e contratações na administração pública federal brasileira: processo decisório e oportunidade política”. In: XIX Congreso Internacional del CLAD sobre la Reforma del Estado y de la Administración Pública. Quito, 11-14 nov./2014. Disponível em: http://repositorio.enap.gov.br/1/1716. Acesso em 06/06/2015.

. "A organização da área de compras e contratações na Administração Pública brasileira: o elo frágil”. In: VII Congresso CONSAD de Gestão Pública. Brasília, 25 a 27/03/2014. Disponível em: http://banco.consad.org.br/handle/123456789/1050. Acesso em 18/01/2016.

FERNANDES, Jorge Ulissses Jacoby. "A importância do Município comprar da micro e pequena empresa". Fórum de Contratação e Gestão Pública - FCGP. Belo Horizonte, ano 7, n. 84 , dez./2008.

FIORENTINO, Luigi (Org.). Lo stato compratore. L'acquisto di beni e servizi nelle publiche amministrazioni. Bologna: Il Mulino, 2007.

FIUZA, Eduardo Pedral Sampaio. "Licitações e contratos no Brasil: a visão dos economistas" In: SALGADO, L. H.; FIUZA, E. P. S. (Ed.). Marcos regulatórios no Brasil: é tempo de rever regras? Rio de Janeiro: Instituto de Pesquisa Econômica Aplicada (IPEA), 2009. 
- e MEDEIROS, Bernardo Abreu de. A agenda perdida das compras públicas: rumo a uma reforma abrangente da lei de licitações e do arcabouço institucional. Texto para discussão $n^{\circ}$ 1990. Rio de Janeiro: Instituto de Pesquisa Econômica Aplicada (IPEA), 2014.

FORGIONI, Paula A. Os fundamentos do antitruste. $7^{\text {a }}$ ed. São Paulo: Editora Revista dos Tribunais, 2014.

FROEB, Luke M.; KOYAK, Robert A.; WERDEN, Gregory J. "What is the effect of bidrigging on prices?" Economics Letters, n 42, 4, January/1993, pp. 419-423.

GARCIA, Flávio Amaral e RIBEIRO, Leonardo Coelho. "Licitações públicas sustentáveis". RDA - Revista de Direito Administrativo, Rio de Janeiro, v. 260, maio/ago. 2012, pp. 231254.

GOLDBERG, Victor P. "Competitive Bidding and the Production of Precontract Information". Bell Journal of Economics, n. 8, 1977, pp. 250-261.

GONÇALVES, Pedro Costa. O Contrato Administrativo: Uma instituição do direito administrativo do nosso tempo. Coimbra: Almedina, 2002.

. "Integração de preocupações concorrenciais nas regras da contratação

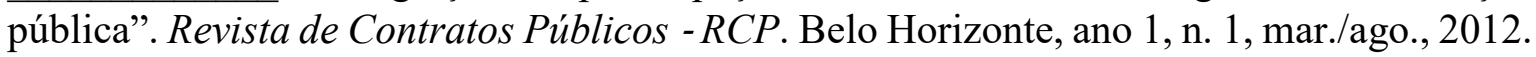

. "A regulação do mercado da contratação pública". Revista de Contratos $\overline{\text { Públicos }-R C P}$, Belo Horizonte, ano 3, n. 3, p. 201-208, mar./ago. 2013

Coimbra editora, 2013.

Reflexões sobre o Estado Regulador e o Estado Contratante. Coimbra:

GRAU, Eros Roberto. Elementos de Direito Econômico. São Paulo: RT, 1981.

. "Constituição e Serviço Público". In: GRAU, Eros Roberto. GUERRA FILHO, Willis Santiago (Orgs.) Direito Constitucional - Estudos em homenagem a Paulo Bonavides. São Paulo: Malheiros, 2001.

Malheiros, 2008.

A Ordem Econômica na Constituição de 1988. $13^{\mathrm{a}}$ ed. São Paulo:

. "Licitação - Dispensa - Notória especialização". Revista de Direito Administrativo, Rio de Janeiro, v. 150, p. 216-226, jan. 2015.

GUASCH, J. Luis. Granting and Renegotiating Infrastructure Concessions: Doing it Right. WBI Development Studies: Washington: World Bank, 2004. Disponível em https://openknowledge .worldbank.org/handle/10986/15024.

GUIMARÃES, Fernando Vernalha e MOREIRA, Egon Bockmann. Licitação Pública. A Lei Geral de Licitação - LGL e o Regime Diferenciado de Contratação - RDC. São Paulo: Malheiros, 2012. 
HATZIS, Nicholas. "The legality of SME development policies under EC procurement law", In: ARROWSMITH, Sue e KUNZLIK, Peter (orgs). Social and environmental policies in EC procurement law. New Directives and New Directions. Cambridge (UK): Cambridge University Press, 2009, pp. 345-368.

JURKSAITIS, Guilherme Jardim e SUNDFELD, Carlos Ari (Coord.) Contratos Públicos e Direito Administrativo. São Paulo: Malheiros, 2015.

JUSTEN FILHO, Marçal. Comentários à Lei de Licitações e Contratos Administrativos. 14a ed. São Paulo: Dialética, 2010.

Pregão (comentários à legislação do pregão comum e eletrônico). $6^{\mathrm{a}}$ ed. São Paulo: Dialética, 2013.

KANG, Karam e MILLER, Robert A. "Winning by Default: Why is There So Little Competition in Government Procurement?" Carnegie Mellon University Discussion Paper. Versão eletrônica disponível em: http://www.econ.ucla.edu /workshops/ papers /Applied /kang_miller_procurement.pdf., Acesso em 06/06/2016.

KATTEL, Rainer e LEMBER, Veiko. "Public Procurement as an industrial policy tool: an option for developing countries?" Journal of Public Procurement, vol.10, issue 3, 2010, pp. 368-404.

KELMAN, Steven. Procurement and Public Management: The Fear of Discretion and the Quality of Government Performance. Washington: The AEI Press, 1990.

KLEMPERER, Paul. Auctions: theory and practice. Princeton (NJ); Oxford (UK): Princeton University Press, 2004.

KOVACIC, W.; MARSHALL, R.; MARX, L.; RAIFF, M.; "Bidding rings and the design of anti-collusive measures for auctions and procurements". In: DIMITRI, N.; PIGA, G.; SPAGNOLO, G. (Ed.). Handbook of procurement. Cambridge (UK): Cambridge University Press, 2006, pp. 381-411.

. "Competition policy, consumer protection and economic disadvantage". Washington University Journal of Law \& Policy. Vol 25, 2007, pp. 101-118.

KRISHNA, Vijay. Auction Theory. $2^{\mathrm{a}}$ ed. Oxford (UK): Academic Press/Elsevier, 2010.

LAMBSDORFF, Johann Graf. The Institutional Economics of Corruption and Reform: Theory, Evidence, and Policy, Cambridge: Cambridge University Press, 2007.

LENGWILER, Yvan e WOLFSTETTER, Elmar. "Corruption in procurement auctions”. In: DIMITRI, N.; PIGA, G.; SPAGNOLO, G. (Ed.). Handbook of procurement. Cambridge (UK): Cambridge University Press, 2006, pp. 412-429.

LIRA, Bruno e NÓBREGA, Marcos. "O Estatuto do RDC é contrário aos cartéis em licitação? Uma breve análise baseada na teoria dos leilões". Revista Brasileira de Direito Público - RBDP. Belo Horizonte, ano 9, n. 35, out./dez. 2011. 
LOUGHLIN, Martin. The Idea of Public Law. Oxford: Oxford University Press, 2003

MARQUES NETO, Floriano de Azevedo. "Público e privado no setor de saúde". Revista de Direito Público da Economia, Belo Horizonte: Fórum, n. 9, jan./mar., 2005, pp. 105-154.

. "Do contrato administrativo à administração contratual". Revista do Advogado. São Paulo: AASP. Ano XXIX, nº 107, dez./2009, pp. 74-82.

MARQUES, Felipe Silveira. Compras Públicas no Brasil e EUA: análise da concorrência segundo o paradigma estrutura-conduta-desempenho. $80 \mathrm{p}$. Monografia premiada em $3^{\circ}$ lugar no X Prêmio Tesouro Nacional - Tópicos Especiais de Finanças Públicas. Brasília: ESAF, 2005.

McAFEE, R. Preston e McMILLAN, John. "Government procurement and international trade”. Journal of international economics, v. 26, n. 3-4, 1989, pp. 291-308

McCRUDDEN, Christopher. "Using public procurement to achieve social outcomes". Natural Resources Forum, nº 28, 2004, pp. 257-267.

MEDAUAR, Odete. Direito Administrativo Moderno. $7^{\mathrm{a}}$ ed. São Paulo: RT, 2003.

MEERHOLZ, André Leonardo. "O preço mínimo na licitação como indicativo de conduta anticoncorrencial". Revista de Direito Público da Economia - RDPE. Belo Horizonte, ano 13, n. 49, pp. 9-25, jan./mar. 2015.

MEIRELLES, Hely Lopes. Direito Administrativo Brasileiro 32ª ed., São Paulo: Revista dos Tribunais, 2006.

MIGUEL, Luiz Felipe Hadlich. "Licitação - Passado, presente e futuro". Fórum de Contratação e Gestão Pública - FCGP, Belo Horizonte, ano 14, n. 158, p. 41-49, fev. 2015.

MILESKI, Helio Saul. "Tratamento diferenciado e favorecido em licitações públicas Aperfeiçoamentos legais introduzidos ao Estatuto Nacional da Microempresa e da Empresa de Pequeno Porte (Lei Complementar $n^{\circ}$ 147/2014)". Revista Interesse Público- IP, Belo Horizonte, ano 16, n. 86, jul./ago. 2014, pp. 51-70.

MINGANTI, Lorenzo e ZUCCOLOTTO, Stefania. "Evoluzione storica del processo d'acquisto della pubblica amministrazione". In: FIORENTINO, Luigi (org.). Lo stato compratore. L'acquisto di beni e servizi nelle publiche amministrazioni. Bologna: Il Mulino, 2007, pp. 47-78.

MILGROM, Paul. "Putting auction theory to work: the simultaneous ascending auction". Journal of Political Economy, vol. 108, nº 2, 2000, pp. 245-272.

Press, 2004.

. Putting auction theory to work. Cambridge (UK): Cambridge University

MONTEIRO, Vera Cristina Caspari. Licitação na Modalidade de Pregão. São Paulo: Malheiros, 2003 
. Concessão. São Paulo: Malheiros, 2010.

MOREIRA, Vital Martins. Auto-regulamentação profissional e Administração Pública. Coimbra: Almedina, 1997.

MOTTA, Alexandre Ribeiro. "Electronic Reverse Auctions in Brazil Federal Government: a critical view". In: 4th Public Procurement Ph.D. Conference Nottingham University, 2009, Nottingham. Anais eletrônicos. Disponível em: http://www.nottingham.ac.uk/pprg/documentsarchive/phdconference2009/alexandre\%20m otta.pdf. Acesso em 30/07/2015.

. "Public Procurement in Brazil Federal Government: a perspective from the agents responsible for its regulation and operation". In: International Public Procurement Conference, Seoul National University, 2010. Disponível em: http://www.ippa.org/IPPC4/Proceedings/01ComparativeProcurement/Paper1-4.pdf. Acesso em 04/02/2015.

O combate ao desperdício no gasto público: uma reflexão baseada na comparação entre os sistemas de compra privado, público federal norte-americano e brasileiro. 2010. 189 p. Dissertação (Mestrado) - Instituto de Economia (IE), Universidade Estadual de Campinas, Campinas, 2010.

NOHARA, Irene Patrícia. "Poder de compra governamental como fator de indução do desenvolvimento - faceta extracontratual das licitações". Revista Fórum de Direito Financeiro e Econômico - RFDFE. Belo Horizonte, ano 4, n. 6, set./fev. 2015, pp. 155-172.

NÓBREGA, Marcos. "Contratos incompletos e infraestrutura: contratos administrativos, concessões de serviço público e PPPs" Revista Eletrônica de Direito Administrativo Econômico-REDAE. Salvador: Instituto Brasileiro de Direito Público, $\mathrm{n}^{\mathrm{o}}$ 18, mai.jul. 2009. Disponível em: http://www.direitodoestado.com/revista/REDAE-18-MAIO-2009MARCOS-NOBREGA.pdf. Acesso em: 18/03/2015.

. Direito da Infraestrutura. São Paulo: Quartier Latin, 2011.

NUSDEO, Fábio. Curso de Economia. Introdução ao Direito Econômico. $5^{\mathrm{a}}$ ed. São Paulo: Revista dos Tribunais, 2008.

OLIVEIRA, Rafael Carvalho Rezende e FREITAS, Rafael Véras de. “A função regulatória das licitações e o desenvolvimento nacional sustentável: o regime jurídico introduzido pela Lei n ${ }^{\circ}$ 12.349/10". Revista Brasileira de Direito Público - RBDP, Belo Horizonte, ano 10, n. 38, jul./set. 2012. Disponível em: http://www.bidforum.com.br/ bid/PDI0006.aspx?pdiCntd=81456. Acesso em: 15/05/2015.

ORGANIZAÇÃO PARA A COOPERAÇÃO E DESENVOLVIMENTO ECONÔMICO OCDE. L'intégrité dans les marchés publics - Les bonnes pratiques de $A$ à Z, OCDE Publishing, 2008. Disponível em: http://www.oecd.org/fr/gov/ethique/lintegritedans lesmarchespublicslesbonnespratiquesdeaaz.htm Acesso em 19/06/2016. 
PEDREIRA, Pedro Matias. GUIMARÃES, Rui Mesquita. "O valor do contrato no Código dos Contratos Públicos português". Revista de Contratos Públicos - RCP. Belo Horizonte, ano 3, n. 5, mar./ago. 2014, pp. 157-177.

PEREIRA JÚNIOR, Jessé Torres. Comentários à Lei de Licitações e Contratos da Administração Pública, Rio de Janeiro: Renovar, 2003.

PERES, Úrsula Dias. "Custos de transação e estrutura de governança no setor público". Revista Brasileira de Gestão de Negócios - RGBN. São Paulo, Vol. 9, n. 24, maio/ago. 2007, pp. 15-30.

PICCI, Lucio. "Reputation-based governance of public works". Rivista di Politica Economica, vol. 96, issue 1, jan./fev. 2006, pp. 161-183.

. "Dal modello CONSIP a un sistema di procurement nazionale". In: FIORENTINO, Luigi (org.). Lo stato compratore. L'acquisto di beni e servizi nelle publiche amministrazioni. Bologna: Il Mulino, 2007, pp. 285-306.

PIGA, Gustavo. "A fighting chance against corruption in public procurement?" In: ACKERMAN, Susan Rose; SOREIDE, Tina (org.). International Handbook on the Economics of Corruption. Vol. II, Cheltenham (UK): Edward Elgar, 2011, pp. 141-181.

. TREUMER, Steen (ed.). The applied Law and Economics of Public Procurement. London/New York: Routledge, 2013.

PINHO, Diva Benevides; VASCONCELOS, Marco Antonio Sandoval de; TONETO JR., Rudinei; (Org). Manual de Economia. 6a ed. São Paulo: Saraiva, 2011.

PINTO, Henrique Motta. Empresa Estatal: modelo jurídico em crise? 200 p. Dissertação (Mestrado). São Paulo: Pontifícia Universidade Católica de São Paulo (PUC/SP), 2010.

PINTO JÚNIOR, Mário Engler. "Parceria Público-Privada. Antigas e novas modalidades contratuais". Revista Digital de Direito Público da Economia - RDPE, Belo Horizonte: Fórum, ano 6, n. 13, jan. 2006.

- PRADO, Lucas Navarro e RIBEIRO, Maurício Portugal; Regime Diferenciado de Contratação: licitação de infraestrutura para a Copa do Mundo e Olimpíadas. São Paulo: Atlas, 2012.

RODRIGUES, Nuno Cunha. A Contratação Pública como Instrumento de Política Económica. Coimbra: Almedina, 2013.

ROLFSTAM, Max. Public Technology Procurement as a Demand-side Innovation Policy Instrument - an Overview of Recent Literature and Events. Lund University Institute of Technology, 2005. Disponível em: http://www2.druid.dk /conferences/viewpaper.php?id=2553\&cf=17. Acesso em: 03/07/2015.

. Understanding public procurement of innovation: definitions, innovation types and interaction modes". Social Science Research Network, Rochester (NY), 26/02/2012. Disponível em: http://goo.gl/N185B9. Acesso em: 22/08/2016. 
REICH, Norbert. Mercado y derecho: Teoria y praxis del derecho economico en la Republica Federal Alemana, tradução espanhola por Antoni Font, Barcelona: Ariel, 1985.

ROSILHO, André Janjácomo. Licitação no Brasil. São Paulo: Malheiros, 2013.

SAUSSIER, Stéphane e TIROLE, Jean. "Strengthening the Efficiency of Public Procurement". Les notes du conseil d'analyse économique. Paris: Conseil d'analyse économique, $\mathrm{n}^{\mathrm{o}}$ 22, abril/2015. Disponível em: https://www.researchgate.net/ publication/275973839_Strengthening_the_Efficiency_of_Public_Procurement. Acesso em 29/06/2015.

SCHWARZ, Jeffery D. "The Use of the Antitrust State Action Doctrine in the Deregulated Electric Utility Industry”. American University Law Review, issue 48, no.6, August, 1999, pp. 1449-1490.

SCHWIND, Rafael Wallbach. "Breves comentários à nova de lei de licitações de serviços de publicidade (Lei 12.232/2010)", Informativo Justen, Pereira, Oliveira e Talamini, Curitiba, $\mathrm{n}^{\mathrm{o}}$ 40, jun./2010, disponível em http://www.justen.com.br//informativo.php?\& informativo $=40 \&$ artigo $=974 \& \mathrm{l}=$ pt. Acesso em 17/10/2016.

SERVIÇO BRASILEIRO DE APOIO ÀS MICRO E PEQUENAS EMPRESAS (SEBRAE). Políticas Públicas - As micro e pequenas empresas e as compras governamentais. Série "Temas em debate", 2005. Disponível em: http://www.sebraesp. com.br/arquivos_site/biblioteca/compras_governamentais.pdf. Acesso em 02/01/2015.

SILVA, Erivam Paulo da. O uso do Poder de Compra do Estado como instrumento de política pública: a Lei Complementar $n^{\circ}$ 123/2006, sua implementação. 180 p. Dissertação (Mestrado). Rio de Janeiro: Escola Brasileira de Administração Pública e de Empresas/FGV, 2008 .

SILVA, Fabiane Tessari Lima da. "A tutela da concorrência no âmbito do Direito Comunitário e a modificação objetiva dos contratos públicos no Código dos Contratos Públicos português (CCP)". Revista de Direito Público da Economia - RDPE, Belo Horizonte, ano 11, n. 43, jul./set.2013, Disponível em: http://www. bidforum.com.br/bid/PDI0006.aspx?pdiCntd=97660. Acesso em: 15/05/2015, pp. 83-108.

SILVA, Marcos Fernandes Gonçalves da. "O controle dos processos de licitação: uma análise de economia política". Estudos Econômicos da Construção. SindusCon-SP, São Paulo, Vol. 2, $\mathrm{n}^{\mathrm{o}}$ 3, 1997. Disponível em: http://gvpesquisa.fgv.br/professor/marcosfernandes-goncalves-da-silva. Acesso em 19/07/2016.

. "Corrupção e produção de bens públicos". In.: ARVATE, Paulo e BIDERMAN, Ciro (Orgs.). Economia do Setor Público no Brasil. Rio de Janeiro: Elsevier, 2004. pp. 127-135.

SØREIDE, Tina. "Beaten by bribery: why not blow the whistle?" Journal of Institutional and Theoretical Economics, n. 164, issue 3, pp. 407-428. 
SOUTO, Marcos Juruena Villela. Direito administrativo contratual: licitações, contratos administrativos. Rio de Janeiro: Lumen Juris, 2004.

- "Licitações e controle de eficiência: repensando o princípio do procedimento formal à luz do 'placar eletrônico'!". Fórum de Contratação e Gestão Pública - FCGP, Belo Horizonte, ano 8, n. 93, set. 2009. Disponível em: http://www.bidforum.com.br/bid/PDI0006.aspx?pdiCntd=62589. Acesso em: 15/05/2015.

SPAGNOLO, Giancarlo. "Reputation, Competition and Entry in Procurement", International Journal of Industrial Organization, vol. 30, n 3, 2012, pp. 291-296

SPECK, Bruno Wilhelm. Inovação e rotina no Tribunal de Contas da União: o papel da instituição superior de controle financeiro no sistema político-administrativo do Brasil. São Paulo: Fundação Konrad Adenauer, 2000.

SPILLER, Pablo T. "An institutional theory of public contracts: regulatory implications". Cambridge: National Bureau of Economic Research (NBER), 2008 (NBER Working Paper, $\mathrm{n}^{\mathrm{o}}$.14.152). Publicado posteriormente In: GHERTMAN, Michel. MÉNARD, Claude (Ed.). Regulation, Deregulation, Re-regulation: Institutional Perspectives. Cheltenham: Edward Elgar Publishing, 2009. pp. 45-66.

SQUEFF, Flávia de Holanda Schmidt. O poder de compras governamental como instrumento de desenvolvimento tecnológico: análise do caso brasileiro. Texto para discussão nº 1922. Rio de Janeiro: Instituto de Pesquisa Econômica Aplicada (IPEA), 2014.

STIGLER, George J.; "A theory of oligopoly”. The Journal of Political Economy. University of Chicago, Volume 72, Issue 1, feb./1964, pp. 44-61

SUNDFELD, Carlos Ari. "Como reformar licitações?", Interesse Público - Revista Bimestral de Direito Público, Belo Horizonte: Fórum, ano 11, n. 54, mar./abr. 2009. Disponível em: http://www.bidforum.com.br/bid/ PDI0006.aspx ?pdiCntd=62589. Acesso em: 17/06/2016.

. (Org.). Contratações Públicas e seu controle. São Paulo: Malheiros, 2013.

. e SOUZA, Rodrigo Pagani. "Licitação nas estatais: levando a natureza empresarial a sério". In: SUNDFELD, Carlos Ari (Org.). Contratações Públicas e seu controle, São Paulo: Malheiros, 2013

TÁCITO, Caio. "Licitação - Carta-convite - Lista Telefônica". Revista de Direito Administrativo, Rio de Janeiro, v. 167, pp. 299-326, jan./mar. 1987.

THAI, Khi V. "Public Procurement re-examined". Journal of Public Procurement, volume 1, issue 1, 2001, pp. 09-50.

THOMAS, Arthur G. Principles of Government Purchasing. New York: D. Appleton and Company, 1919.

VICKREY, William. "Counterspeculation, Auctions, and Competitive Sealed Tenders", Journal of Finance, vol. 16, issue 1, mar./1961, pp. 8-37. 
WAHRLICH, Beatriz M. de Sousa. "Reforma administrativa federal brasileira: passado e presente". Revista de Administração Pública, Rio de Janeiro, v. 8, n 2, p. 27-75, 1974.

WALD, Arnoldo. "Algumas considerações sobre o novo projeto de lei de licitações (PL 59/92)". Revista Tributária e de Finanças Públicas, vol. 4, jul/set/1993, pp. 198-220.

WILLIAMSON, Oliver E.; The economic institutions of capitalism: firms, markets, relational contracting. New York: The Free Press, 1985.

WILLOUGHBY, William F., Principles of public administration, Washington: Brookings, 1927.

\section{ÍNDICE DE TABELAS, FIGURAS E GRÁFICOS}

Tabela 1 - "Gestão" e "controle" nas quatro fases das licitações no Brasil

p.

Figura 1- Versão estendida da "matriz de Hommen"

Tabela 2- Jurisprudência do STF sobre objetivos horizontais em contratações públicas

Tabela 3 - Comparando contratos de preço fixo e contratos de reembolso

Gráfico 1 - Propostas recebidas por contrato na França entre 2005 e 2007

Tabela 4 - Tipos de procedimento de adjudicação versus números de propostas recebidas nos EUA entre 2004 e 2012

Gráfico 2 - Uso de diferentes procedimentos de adjudicação em alguns países europeus

Tabela 5 - Complexidade do objeto como critério para a "modelagem" da contratação

Gráfico 3 - Frequência de corrupção em contratações públicas

Tabela 6 - Os dois problemas no funcionamento de cartéis: "coordenação" e "enforcement"

Figura 2 - Os sinais mais comuns de colusão em licitações 